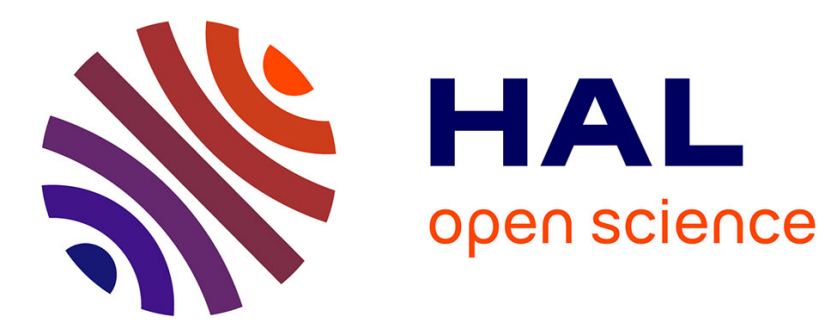

\title{
Effects of interactive vegetation phenology on the 2003 summer heat waves
}

Marc Stéfanon, Philippe Drobinski, Fabio d'Andrea, Nathalie de

Noblet-Ducoudré

\section{- To cite this version:}

Marc Stéfanon, Philippe Drobinski, Fabio d'Andrea, Nathalie de Noblet-Ducoudré. Effects of interactive vegetation phenology on the 2003 summer heat waves. Journal of Geophysical Research: Atmospheres, 2012, 117 (24), pp.D24103. 10.1029/2012JD018187 · hal-01111701

\author{
HAL Id: hal-01111701 \\ https://hal.science/hal-01111701
}

Submitted on 30 Jan 2015

HAL is a multi-disciplinary open access archive for the deposit and dissemination of scientific research documents, whether they are published or not. The documents may come from teaching and research institutions in France or abroad, or from public or private research centers.
L'archive ouverte pluridisciplinaire HAL, est destinée au dépôt et à la diffusion de documents scientifiques de niveau recherche, publiés ou non, émanant des établissements d'enseignement et de recherche français ou étrangers, des laboratoires publics ou privés. 


\title{
Effects of interactive vegetation phenology on the 2003 summer heat waves
}

\author{
Marc Stéfanon, ${ }^{1}$ Philippe Drobinski, ${ }^{1}$ Fabio D'Andrea, ${ }^{1}$ and Nathalie de Noblet-Ducoudré ${ }^{2}$ \\ Received 31 May 2012; revised 24 September 2012; accepted 15 October 2012; published 20 December 2012.
}

[1] This paper investigates the impact of accounting for interactive plant phenology on the simulation of the June and August 2003 European heat waves. A sensitivity analysis is conducted here by using the WRF atmospheric model and the ORCHIDEE land-surface model over France with (1) a prescribed vegetation corresponding to year 2002 and (2) a dynamical vegetation model that leaves the vegetation freely evolving. It has been found that, accounting for the phenology dynamics has opposite effects on both events, it damps the temperature anomaly in June, while it amplifies the temperature anomaly in August. The evolution of leaf area index in the two simulations reveals the early and fast development of agricultural vegetation in the simulation with freely evolving vegetation. The vegetation also decays earlier in 2003 than during normal years. This behavior has two consequences. In June, the larger foliage development, caused by higher springtime insolation, contributes to enhanced evapotranspiration and therefore land surface cooling which limit the temperature anomaly during the heat wave. This effect is not as visible in mountainous regions where the presence of forest and the absence of agriculture do not lead to the same modulation of the local water cycle. In August, the early leave fall and the critical soil moisture stress contribute to largely suppress evapotranspiration and to enhance sensible heat flux thus amplifying the temperature anomaly. The modulation of the temperature anomaly caused by the effect of interactive vegetation phenology can reach $\pm 1.5^{\circ} \mathrm{C}$ for an average total anomaly of about $8^{\circ} \mathrm{C}$ (i.e. $\pm 20 \%$ ).

Citation: Stéfanon, M., P. Drobinski, F. D’Andrea, and N. de Noblet-Ducoudré (2012), Effects of interactive vegetation phenology on the 2003 summer heat waves, J. Geophys. Res., 117, D24103, doi:10.1029/2012JD018187.

\section{Introduction}

[2] Heat waves are a serious threat for society which can have dramatic consequences. Typical examples are the summer of 1995 in Chicago [Semenza et al., 1996], summers 1976 [Ellis et al., 1980] and 2003 in Europe or summer 2010 in Russia [Barriopedro et al., 2011]. The 2003 event was at the origin of 15,000 extra deaths in France [Hémon and Jougla, 2003] and 70,000 in 12 European Countries [Robine et al., 2008]. The remarkable intensity of this heat wave - the warmest over the last 500 years over Europe according to Luterbacher et al. [2004] - gave rise to a number of studies that highlighted its impacts on the economic and ecological systems, through reduction in productivity of natural and cultivated vegetation [Ciais et al., 2005; COPA-COGECA, 2003], lower energy supply and electricity restriction owing to the

\footnotetext{
${ }^{1}$ Laboratoire de Météorologie Dynamique, Institut Pierre Simon Laplace, CNRS/École Polytechnique/ENS/UPMC, Palaiseau, France.

${ }^{2}$ Laboratoire des Sciences du Climat et de l'Environnement, Institut Pierre Simon Laplace, CEA/CNRS/UVSQ, Gif-sur-Yvette, France.

Corresponding author: M. Stéfanon, Laboratoire de Météorologie Dynamique, Institut Pierre Simon Laplace, École Polytechnique, Plateau de Palaiseau, Route de Saclay, FR-91128 Palaiseau CEDEX, France. (marc.stefanon@1md.polytechnique.fr)

(C)2012. American Geophysical Union. All Rights Reserved. 0148-0227/12/2012JD018187
}

lack of cooling water [Fink et al., 2004], and an increase of air pollution [Vautard et al., 2005].

[3] Although such heat waves are exceptional, several studies have shown that, associated with an increase of the temperature mean and variability in the context of global warming, these phenomena have become not only more frequent but also longer and more intense during the twentieth century [Easterling et al., 2000; Räisänen, 2002; Klein Tank and Konnen, 2003; Klein Tank et al., 2005; Della-Marta et al., 2007], and this trend could continue in the twentyfirst century [Beniston, 2004; Schär et al., 2004; Ballester et al., 2010; Fischer and Schär, 2010].

[4] Many physical mechanisms related to heat waves in Europe have been studied: large-scale effects, possible teleconnections with tropics, influence of the sea surface temperature and land-atmosphere interactions (for an extensive review, see Garcia-Herrera et al. [2010] and Xoplaki et al. [2012]). During drought, land-atmosphere interactions can amplify the temperature anomaly by increasing the sensible heat flux locally [Fischer et al., 2007; Ferranti and Viterbo, 2006]. When soil moisture is limited due to a long period of rainfall deficit, latent heat flux is reduced and most of the energy is released in the form of sensible heat flux. In Europe, the effect of drought can also be non-local with cloudiness anomaly being advected from Southern Europe, where soil water stress is frequent, toward the North [Zampieri 


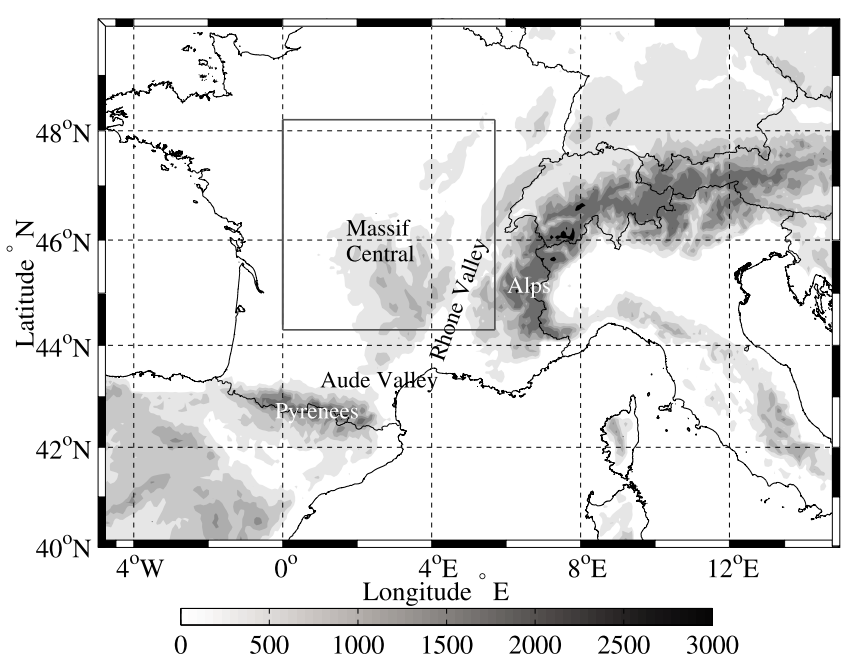

Figure 1. The gray box indicates the integration domain of the MORCE simulations performed to analyze the effect of atmosphere/vegetation feedbacks on the 2003 summer temperature anomaly. The gray shading indicates the height of the orography $(\mathrm{m})$.

et al., 2009; Vautard et al., 2007; Stéfanon et al., 2012]. The sum of several of the mechanisms described above can produce heat waves with an associate temperature anomalies of several degrees.

[5] In this article, we address a question that has never been investigated at such regional scale so far: Does the vegetation contribute to the heat wave temperature anomaly? The interactions between climate and vegetation emerged as a subject of investigation in the 1990s with the development of new satellite products that provided an assessment of vegetation cover and inputs for land-surface models (LSMs). However, these studies were mainly one way investigation.

[6] Bounoua et al. [2000] examined the sensitivity of a general circulation model (GCM) to changes in leaf area index. A cooling during the growing season was observed in midlatitudes, but the model did not take into account the effects of water limitation on LAI and vegetation. $L u$ and Shuttleworth [2002] carried similar investigation over the Colorado with a regional climate model (RCM). They found that the spatial heterogeneity of LAI has a larger impact on the regional water cycle than its seasonal variations, since it induces mesoscale circulations which may trigger moist convection and precipitation.

[7] More recently, advanced experiments have been performed with dynamical vegetation schemes included in LSMs for global scale [Foley et al., 1998; Bonan et al., 2003] or regional scale studies [Jung et al., 2007; Vetter et al., 2008; Anav et al., 2010; Morales et al., 2005; Santaren et al., 2007; Keenan et al., 2009; Mahecha et al., 2010] in order to assess carbon and water flux and cycle over measurement sites. However, in these studies the vegetation/atmosphere feedbacks were not investigated, since this would request a fully coupled numerical model at high resolution. LSMs explicitly consider the role of vegetation in affecting water and energy balance by taking into account its physiological properties, in particular, leaf area index (LAI) and stomatal conductance. These two physiological properties are also the basis of evapotranspiration parameterizations in physically based hydrological models. Although the representation of vegetation so far is simplified, the most current LSMs and hydrological models do not parameterize vegetation as a dynamic component. The seasonal evolution of LAI is prescribed, and monthly or daily LAI values are kept constant year after year.

[8] In this paper, we investigate the role of interactive vegetation phenology on the temperature anomaly of the 2003 summer heat wave, and quantify its potential impact with a two-way land atmosphere coupling run at highresolution $(15 \mathrm{~km})$. Phenology is explicitly resolved by the LSM, thus LAI has a seasonal cycle related to atmospheric and soil moisture states. The high-resolution sheds light on the spatial structure of regional vegetation and its link with temperature extremes. The domain simulation is shown in Figure 1 is located within one of the areas where heat-wave patterns appear recurrently [Stéfanon et al., 2012] and strong soil-atmosphere interactions is a key elements of heat-wave preconditioning [Vautard et al., 2007; Fischer et al., 2007]. It is situated in a transitional area compounded of several ecosystems, and between different types of terrain (plain, mountain). Moreover it is on both sides of $46^{\circ} \mathrm{N}$ parallel, marking the sharp transitional zone between the Mediterranean dry and the European continental climate [Köppen, 1936; Peel et al., 2007].

[9] For this purpose, we use the Weather Research and Forecasting (WRF) atmospheric model coupled with the ORCHIDEE (ORganizing Carbon and Hydrology In Dynamic EcosystEms) land-surface model, which includes a hydrological component, carbon accumulation and allocation, and a dynamical vegetation scheme. A comparison of simulations performed with prescribed and dynamically evolving phenology is carried out.

[10] This paper is organized as follows. Section 2 includes a description of summer 2003 in literature. The methodology and simulations carried out are presented in section 3 with a brief validation. The results of the different simulations are compared, and the differences and similarities are described in section 4 . The processes involved are presented in section 5 showing the connections of temperature, soil moisture, evapotranspiration (ETP) and vegetation. Conclusion is given in section 6.

\section{The 2003 Summer Heat Wave: A Review}

[11] 2003 was one of the warmest years recorded during the period of world-wide instrumental records (beginning in approximately 1880) [Levinson and Waple, 2004]. At the continental - European - scale two distinct periods of exceptional heat occurred during the summer season, the first in the second week of June and the second in the first two weeks of August. The latter was by far the warmest since it coincided with the normal peak of summer temperatures. Schär et al. [2004] highlighted that these months had respectively a temperature offset of 5.3 and 4.1 standard deviations from the mean summer temperature over 1864-2003 in Switzerland. Figure 2 shows the 2003 summer anomaly with respect to the climatology (1950-2009) of the daily maximum surface temperature from the European Climate Assessment \& Data (ECA\&D; Tank et al. [2002]) averaged over the area $44^{\circ} \mathrm{N}-$ $48^{\circ} \mathrm{N}, 0^{\circ} \mathrm{E}-6^{\circ} \mathrm{E}$ (see Figure 1). It allows the accurate identification of the beginning and end of the two heat waves. The first heat-wave starts on June, 8 and ends on June, 16. 


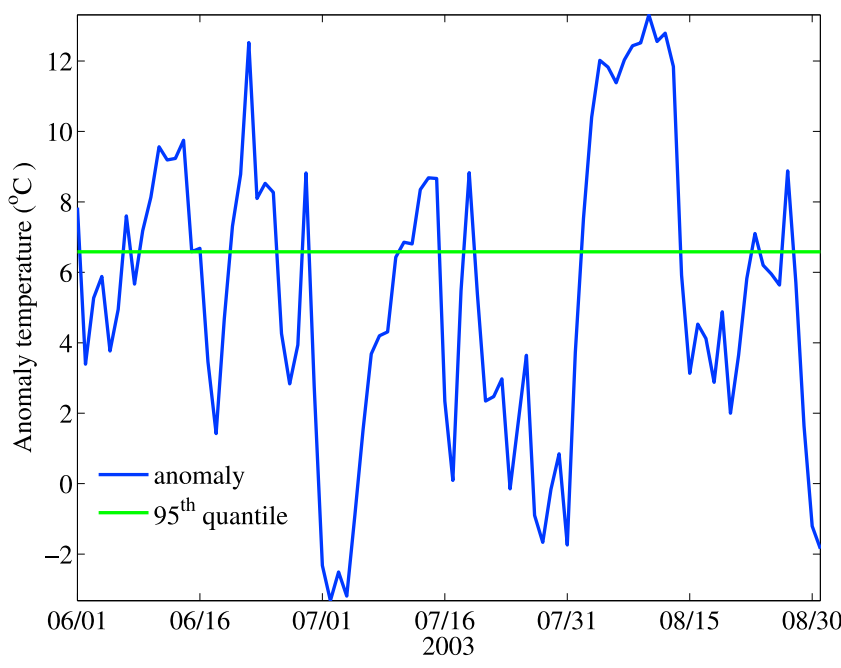

Figure 2. Time series of the 2003 temperature anomaly with respect to the climatology of the daily maximum surface temperature from the European Climate Assessment \& Data (ECA\&D) averaged over the area $44^{\circ} \mathrm{N}-48^{\circ} \mathrm{N}, 0^{\circ} \mathrm{E}-$ $6^{\circ} \mathrm{E}$ (see Figure 1, gray box). The temperature anomaly is indicated in blue and the 95th summer quantile is indicated in green, with respect to 1950-2009 climatology.

August sequence is the most intense and longest with 15 days, it starts on August, 2 and ends on August, 16 and includes 12 days exceeding the 99th percentile of the 1950 2009 period.

[12] The year 2003 was also a very dry year with a persistent precipitation deficit, interrupted intermittently by local and intense heavy rainfall producing floods [Christensen and Christensen, 2003]. The precipitation deficit was exceptional in February and March 2003 and lasted until the end of summer 2003 [Fink et al., 2004]. Precipitation deficit affected local soil moisture, enhancing sensible heat flux and surface temperature [Vautard et al., 2007; Fischer et al., 2007]. Several model output quantified the contribution of soil moisture deficit to the summer 2003 temperature anomaly to about $40 \%$ [Ferranti and Viterbo, 2006; Fischer et al., 2007]. Dryness is also assessed by satellite imagery. van der Velde et al. [2011] analyzed the relationship between soil moisture (from the Advanced microwave Scanning radiometer AMSR-E) and crop yield at regional scale in France. They found that wheat loss was the strongest in 2003 (with respect to the 2002-2007 period), significantly correlated with the soil moisture anomaly. Loew et al. [2009] use products from ENVISAT to investigate soil dynamics and reveals also a negative soil moisture anomaly since March 2003.

[13] Others studies using several remote sensing products have been performed to investigate the heat wave and drought impact on vegetation in 2003. Satellite are better suited to estimate vegetation parameters at global and regional scale. They measure the land surface temperature which is strongly related to air temperature, but also depends of latent heat flux. Thus it depicts a better estimation of vegetation condition. Ciais et al. [2005] show the biosphere reaction in 2003 compared to 2000-2002 with the fraction of absorbed photosynthetically active radiation (FAPAR). The decrease in foliar surface was especially strong in the center of France with $30 \%$ less radiation. Reichstein et al. [2007] confirm this result and find that 2003 was exceptionally low in terms of vegetation activity, compared to the 20 previous years. Jolly et al. [2005] highlight also a global shortening of the growing season length in plain areas, in 2003 with respect to the period 2000-2004. Zaitchik et al. [2006] performs an analysis of normalized difference vegetation index (NDVI), sensible heat flux and temperature from several satellite images. They point out that the temperature anomaly was greater for croplands than for forested lands during the heat waves.

\section{Experimental Design}

[14] The model used in this study is the MORCE (Model of the Regional Coupled Earth system) platform [Drobinski et al., 2012]. It has been designed to investigate the role of coupled processes on the regional climate of particularly vulnerable areas. It has been used in the Hydrological cycle in the Mediterranean experiment (HyMex) [Drobinski et al., 2009, 2010] and the Coordinated Downscaling Experiment (CORDEX) of the World Climate Research Program (WCRP) [Giorgi et al., 2009].

\subsection{The Atmospheric Model}

[15] The atmospheric model of the MORCE platform is the Weather Research and Forecasting (WRF) model of the National Center for Atmospheric Research (NCAR) [Skamarock et al., 2008]. In this article the domain covers part of continental France with a horizontal resolution of $15 \mathrm{~km}$ (see gray box in Figure 1). It has 28 sigma-levels in the vertical. Initial and lateral conditions are from the ERA-Interim reanalysis of ECMWF [Dee et al., 2011; Simons et al., 2007] provided every 6 hours with a $0.75^{\circ}$ resolution. A complete set of physics parameterizations is used with the WRF SingleMoment 3-class microphysical scheme [Hong et al., 2004], the new Kain-Fritsch convection scheme [Kain, 2004], the Yonsei University (YSU) planetary boundary layer (PBL) scheme [Noh et al., 2003] and a parameterization based on the similarity theory [Monin and Obukhov, 1954] for the turbulent fluxes. The radiative scheme is based on the Rapid Radiative Transfer Model (RRTM) [Mlawer et al., 1997] and the Dudhia [1989] parameterization for the longwave and shortwave radiation, respectively. The simulation domain is sufficiently small to produce strong control of the simulations by the boundary conditions and avoid unrealistic departures from the driving fields [Omrani et al., 2012], thus no nudging is applied here.

\subsection{The Land Surface Model}

[16] In the MORCE platform, the dynamical global vegetation model ORCHIDEE is implemented in the atmospheric module WRF. ORCHIDEE is based on three different modules [Krinner et al., 2005]. The first module, called SECHIBA, describes the fast processes such as the soil water budget and the exchanges of energy, water and $\mathrm{CO} 2$ through photosynthesis between the atmosphere and the biosphere [Ducoudré et al., 1993; De Rosnay and Polcher, 1998]. The phenology and carbon dynamics of the terrestrial biosphere are simulated by the STOMATE module. STOMATE essentially simulates processes as maintenance and growth respiration, carbon allocation, litter decomposition, soil carbon dynamics, and phenology [Viovy and de Noblet-Ducoudré, 1997]. 


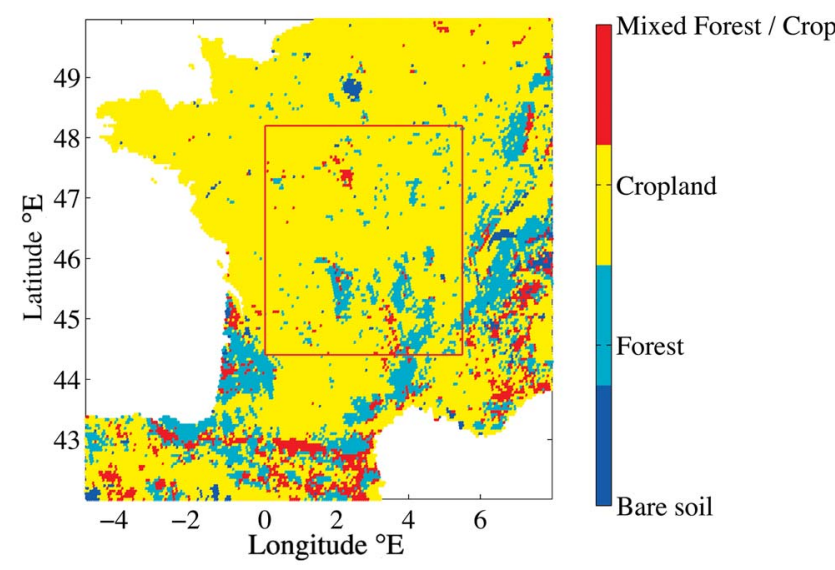

Figure 3. Vegetation distribution according to IGBP-DIS vegetation map at $5^{\prime}$ resolution. For the sake of clarity, vegetation types are deliberately grouped into 4 main categories: Bare soil, Forested areas, Cropland, and a mixture from the last two. The red box indicates the domain of the MORCE simulations.

[17] Hydrology in SECHIBA [Ducoudré et al., 1993; De Rosnay and Polcher, 1998] relies on Choisnel scheme [Choisnel et al., 1995]. Soil is composed of two layers of variable depths, a superficial and a lower one. The total depth is two meters. Storage capacity (i.e. the difference between field capacity and wilting point) is prescribed to $300 \mathrm{~mm}$. Soil moisture in the upper layer is the most reactive. It is determined by moisture convergence but is more complex than a bucket since its depth varies in time. If rainfall occurs, soil is filled from top to bottom and when evapotranspiration exceeds rainfall, water is removed from the upper level where it is available. Hydrological balance is computed for each plant functional type (PFT), and the various water reservoirs are independent horizontally. Latent heat is the sum, per grid cell, of snow sublimation, soil evaporation and canopy evapotranspiration. All those fluxes depend on series of resistances (aerodynamic, canopy, architectural and soil resistances). Stomatal conductance is evaluated by an empirical function that is proportional to the product of photosynthesis and atmospheric relative humidity and is inversely related to $\mathrm{CO} 2$ concentration at the leaf surface [Ball, 1987; Collatz et al., 1991; Farquhar et al., 1980]. Control of evapotranspiration by plants is proportional to soil water stress and is done through a water uptake function. It is related to the exponential structure of the root system and vertical soil moisture profile and represents the root ability to extract water from the soil at a given humidity. The soil water stress coefficient varies between 0 and 1 . High stress is associated with low value, while high values close to 1 indicate a low water stress and an evapotranspiration maximum. Albedo and surface roughness are calculated, per grid cell, as a linear combination of PFT and bare soil. Surface roughness depends on tree height and LAI. Constant albedo values are prescribed for each PFT's leaves and for bare soil, while the total albedo depends on soil color and moisture [Wilson and Henderson-Sellers, 1985], PFT type and LAI.

[18] The vegetation map is based on a $5 \mathrm{~km} \times 5 \mathrm{~km}$ map which is derived from IGBP-DIS map (International Geosphere Biosphere Programme - Data and Information System) with Olson classification [Loveland et al., 2000] and projected onto ORCHIDEE's 12 plant functional types plus desert (Figure 3). The vegetation distribution is strongly dominated by croplands, present in $88 \%$ of the domain, whereas forest and mixed vegetation account for 10 and $2 \%$, respectively. Forests are located mainly in Southern France and on mountain slopes whereas they are very scattered in Northern France.

\subsection{Numerical Experiments}

[19] Two simulations are performed driven by ERAINTERIM for the years 2002 and 2003. Both use ORCHIDEE as LSM with SECHIBA and STOMATE modules activated. It implies an identical computation of stomatal resistance with the same impact of atmospheric carbon. The first, called CTL, was conducted using a prescribed LAI. The effect of vegetation was thus limited to stomatal resistance only. The second simulation called MORCE, uses an explicitly calculated LAI. The prescribed LAI in CTL for 2003 is that of the year 2002 obtained with the MORCE simulation with interactive vegetation. Both simulations begin with the same initial state conditions for the soil state. This is computed by a 5 years spin up integration using the conditions of the year 2002 repeated five times with ORCHIDEE in offline mode. Atmospheric inputs for this spin up are provided by WRF simulation with the NOAH LSM.

[20] 2002 over the domain was not a very abnormal year, slightly dry during the spring but with usual summer temperature (not shown). Concerning the LAI, GEOLAND2 data [Baret et al., 2012] shows that the summer 2002 in France was an average summer with respect to a 1999-2008 climatology [Szczypta, 2012].

[21] The simulation domain covers most of France (Figure 1) and includes the Massif Central bordering the Rhône Valley along its Eastern slope and the Aude valley along its Western slope. The differences between the MORCE and CTL simulations provide an estimate of the impact of vegetation dynamics on the dynamics of the heatwaves. We analyze the response in terms of anomaly of temperature, surface heat flux, and vegetation parameters (LAI, gross primary production GPP).

\subsection{Validation of Temperature}

[22] Comparison of the CTL simulation with observation has been carried out for surface temperature in order to show the overall performance of the coupled system, with respect to other configuration of WRF. We use the E-OBS 3.0 gridded data set of the European Climate Assessment \& Data (ECA\&D) [Tank et al., 2002] for maximum continental surface temperature and precipitation [Haylock et al., 2008].

[23] During summer (June-July August, i.e. JJA), WRF usually displays a bias for the midlatitudes with respect to ECA\&D. For instance with the rapid update cycle (RUC) LSM [Smirnova et al., 1997, 2000] a warm bias of approximately 3 or $4^{\circ} \mathrm{C}$ is observed for the daily mean temperature [Flaounas et al., 2012], and for the thermal diffusion LSM [Skamarock et al., 2008; Eckel, 2002] we observe a cold bias of $-4^{\circ} \mathrm{C}$ [Flaounas et al., 2012]. The use of ORCHIDEE produces a lower bias up to $0.2^{\circ} \mathrm{C}$ on summer 2003 for CTL. If we consider the daily maximum temperature over the heat wave periods for CTL, the root mean square error reaches 0.53 and $1.99^{\circ} \mathrm{C}$ for June and August, respectively. 

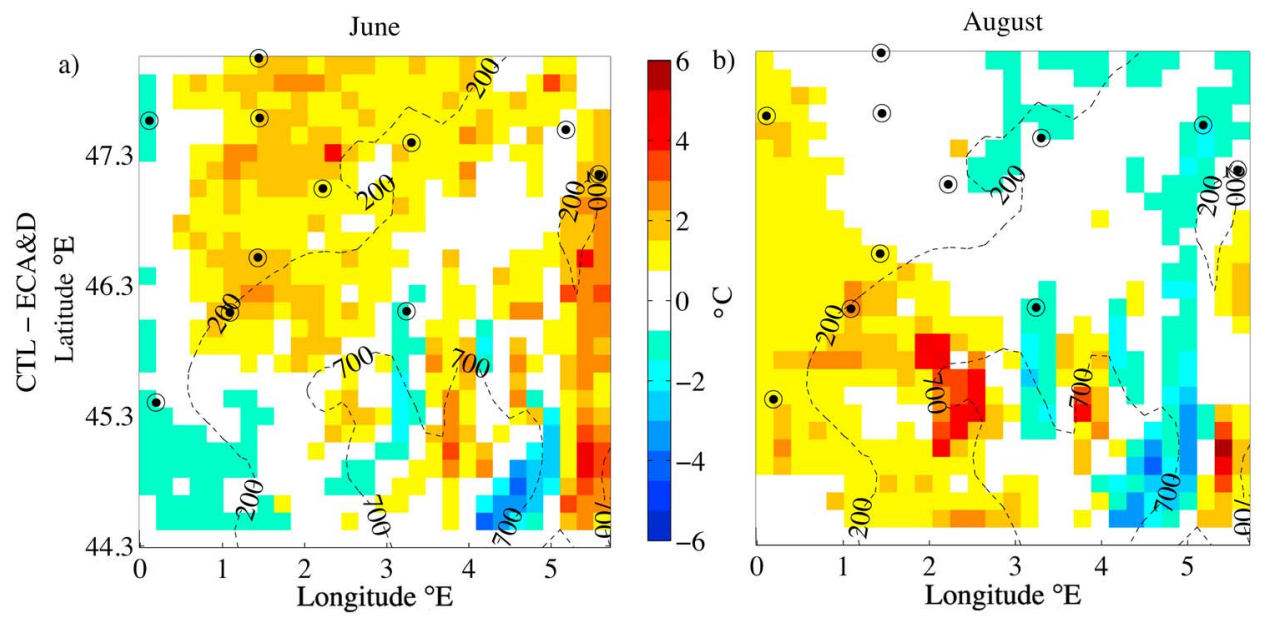

Figure 4. Difference in daily maximum surface temperature between the CTL simulation minus the ECA\&D gridded data set: (a) June heat wave and (b) August heat wave. Dashed lines are height of topography. Dotted black circles indicate the location of stations used by ECA\&D.

[24] The temperature difference between the CTL simulation and the ECA\&D data set during these heat waves is displayed in Figure 4. An important discrepancy (up to $6^{\circ} \mathrm{C}$ ) can be seen in the South-Western subdomain in correspondence of mountains. This local error is the main caveat to the results presented in this paper, but does not put the general results at risk.

[25] Nevertheless we should add that ECA\&D can possibly introduce some further uncertainties in the estimate of this bias itself. The E-OBS 3.0 data set is interpolated at high resolution $(25 \mathrm{~km})$ from 2000 stations over Europe [Haylock et al., 2008]. For our particular case, the data station are unfortunately quite far from the high bias area of the SW sector of the domain (see Figure 4).

\section{Simulation Results}

[26] Figure 5 displays the differences between MORCE and CTL simulations at 1500 UTC (warmest period of the day) for surface temperature and latent heat flux (equal to the evapotranspiration from plant and bare soil, multiplied by the water specific latent heat vaporization) averaged over the periods of heat waves as defined in section 2. It shows important temperature differences between the two simulations. In June 2003, the MORCE simulation is colder than the CTL simulation. On average the temperature difference is $-0.55^{\circ} \mathrm{C}$ and can reach $-2.5^{\circ} \mathrm{C}$ in Northern France. In South-Western France, the difference between the two simulations is not significant. The situation in August is reversed with respect to the situation in June. The MORCE simulation is on average $0.39^{\circ} \mathrm{C}$ warmer and exhibits temperatures up to $2.2^{\circ} \mathrm{C}$ higher in the Western area with respect to the CTL simulation. Only the high elevation areas in the Massif Central are colder by about $1.3^{\circ} \mathrm{C}$ with respect to the CTL simulation. The most remarkable feature is the very strong anti-correlation of about -0.7 between the temperature anomaly and the latent heat flux anomaly patterns. In June 2003, the most negative temperature anomaly (about -1 to $-1.5^{\circ} \mathrm{C}$ ) corresponds to a positive anomaly of latent heat flux of about $+100 \mathrm{~W} \mathrm{~m}^{-2}$ (Figures $5 \mathrm{a}$ and $5 \mathrm{~b}$ ). In August 2003, the positive temperature anomaly (about +1 to $+1.5^{\circ} \mathrm{C}$ ) corresponds to a negative anomaly of latent heat flux of about $-100 \mathrm{~W} \mathrm{~m}^{-2}$ (Figures $5 \mathrm{c}$ and $5 \mathrm{~d}$ ).
[27] Figure 6 displays similar diagnosis as Figure 5 for sensible heat flux and solar net radiation. The sensible heat flux anomaly pattern is of opposite sign to the latent flux anomaly with at most $115 \mathrm{~W} \mathrm{~m}^{-2}$ difference. Regarding the solar flux, it is on average 660 and $690 \mathrm{~W} \mathrm{~m}^{-2}$, for June and August, respectively. It displays very little difference between the MORCE and CTL runs for August, because of the absence of clouds in the two simulations, except along the mountain slopes where the MORCE simulations produces slightly less clouds. The difference is locally higher for June with a higher cloud cover in the MORCE simulations, consistently with the higher evapotranspiration. The difference can exceed $90 \mathrm{~W}$ $\mathrm{m}^{-2}$ in the center of the domain and is on average $10 \mathrm{~W} \mathrm{~m}^{-2}$ over an area in Central France representing 38\% of the total domain size. A difference of $10 \mathrm{~W} \mathrm{~m}^{-2}$ in latent and sensible heat flux is found over an area representing $80 \%$ and $90 \%$ of the total domain, respectively. The spatial correlation between temperature and latent heat flux pattern (Figures $5 \mathrm{a}$ and $5 \mathrm{~b}$ ) is 4.5 higher (in absolute value) than the correlation between temperature and net solar radiation pattern (Figures 5a and 6a). The difference of albedo between the MORCE and CTL simulations can be analyzed using the reflected (i.e. upward) short wave radiation (Figure 7). The difference between the two simulations is low when averaged over domain, with 5.5 and $2.5 \mathrm{~W} \mathrm{~m}^{-2}$ in June and August, respectively. Thus the foliage development does not impact albedo on cropland area. Nevertheless along mountain slopes, where forest vegetation is dominant, it is up to $50 \mathrm{~W} \mathrm{~m}^{-2}$ and explains most of the difference in net solar radiation during August heat wave (Figure 6c).

[28] Cutting the domain in four sub-domains of equal size delimited by the gray lines in Figures 5 and 6, shows evidence of different responses to the effect of interactive vegetation (Figures 5 and 6). If the two Northernmost subdomains have similar behavior, the two Southernmost subdomains display significantly different behaviours. In June, the MORCE simulation is colder than the CTL simulation over Northern and South-Eastern France over Massif Central. The difference is not significant in South-Western France. In August, the MORCE simulation is warmer than the CTL simulation over Northern and South-Western France, 

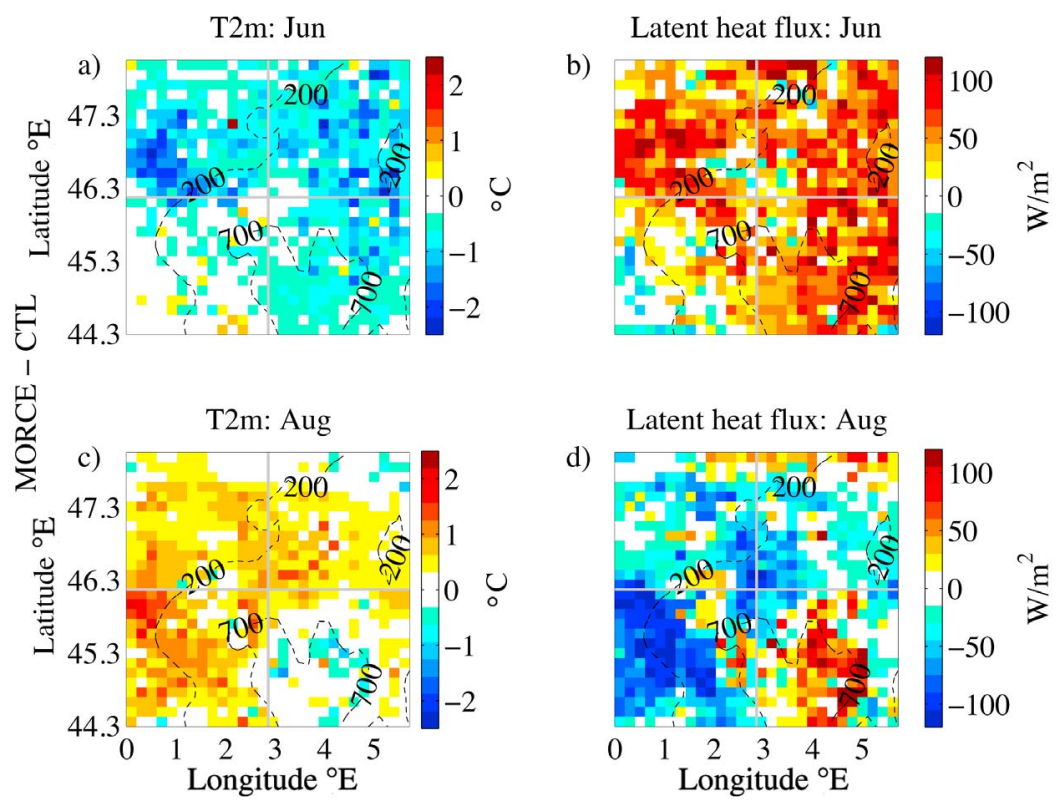

Figure 5. Difference between the MORCE and CTL simulations over the domain indicated by a gray box in Figure 1 for the $(\mathrm{a}, \mathrm{c})$ 2-m temperature and $(\mathrm{b}, \mathrm{d})$ latent heat flux at 1500 UTC averaged over the heat wave period in June 2003 (Figures 5a and 5b) and August 2003 (Figures 5c and 5d). Dashed lines are height of topography.

whereas it is slightly colder over South-Eastern France. In the South-Eastern subdomain, the presence of the Massif Central controls part of the hydrological response with lower soil water stress and different vegetation types than over the rest of the domain (Figure 3).

[29] Figure 8 shows the time series of the daily average difference between MORCE and CTL simulations for surface temperature and evapotranspiration for the four subdomains. From April to June, the afternoon evapotranspiration is about $40 \%$ higher in MORCE simulations which is equivalent to $1.2 \mathrm{~mm} \mathrm{day}^{-1}$ additional water released in the atmosphere over the whole domain. In June, the MORCE excess of evapotranspiration with respect to the CTL run decreases until it reverses at the end of July just before the August heat wave. The reversal is especially important in the northern part of the domain where the differences are strong - about $1.65 \mathrm{~mm}$ day ${ }^{-1}$ and $0.7^{\circ} \mathrm{C}$ - during the June heat wave. It is lower in the South Western subdomain $\left(0.6 \mathrm{~mm} \mathrm{day}^{-1}\right.$ and $\left.0.2^{\circ} \mathrm{C}\right)$ because
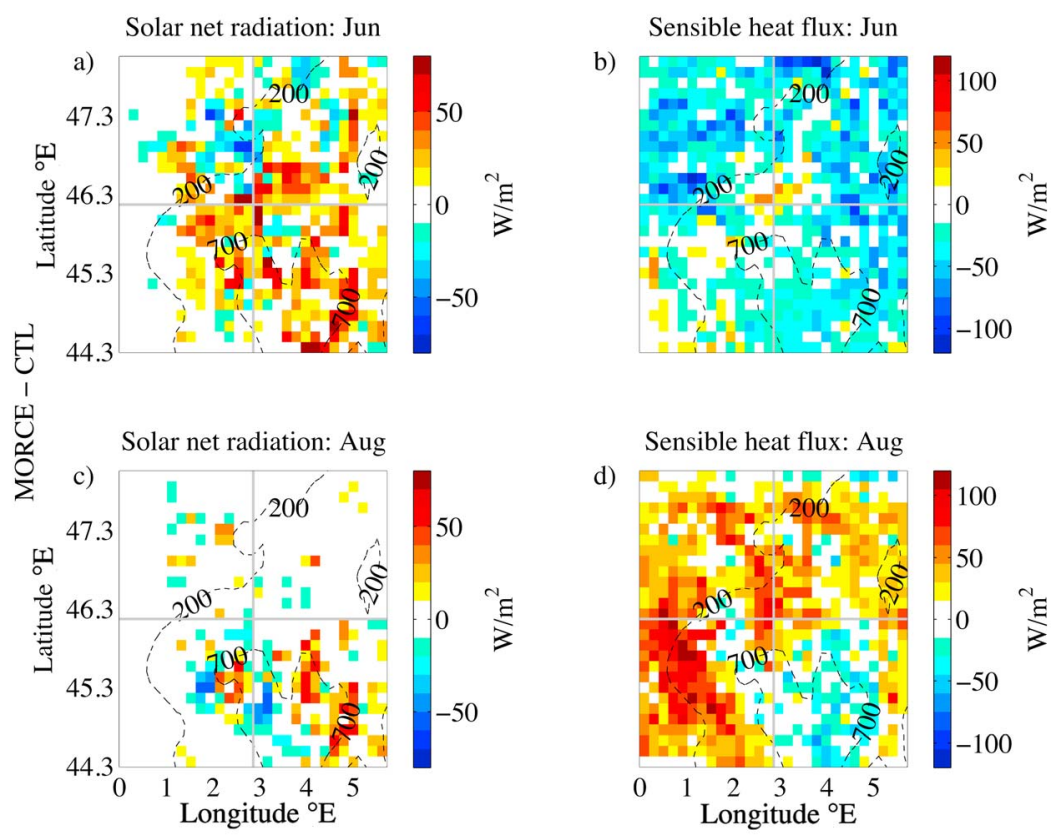

Figure 6. Similar to Figure 5 for the $(a, c)$ net solar radiation and $(b, d)$ sensible heat flux in June 2003 (Figures 6a and 6b) and August 2003 (Figures 6c and 6d). 

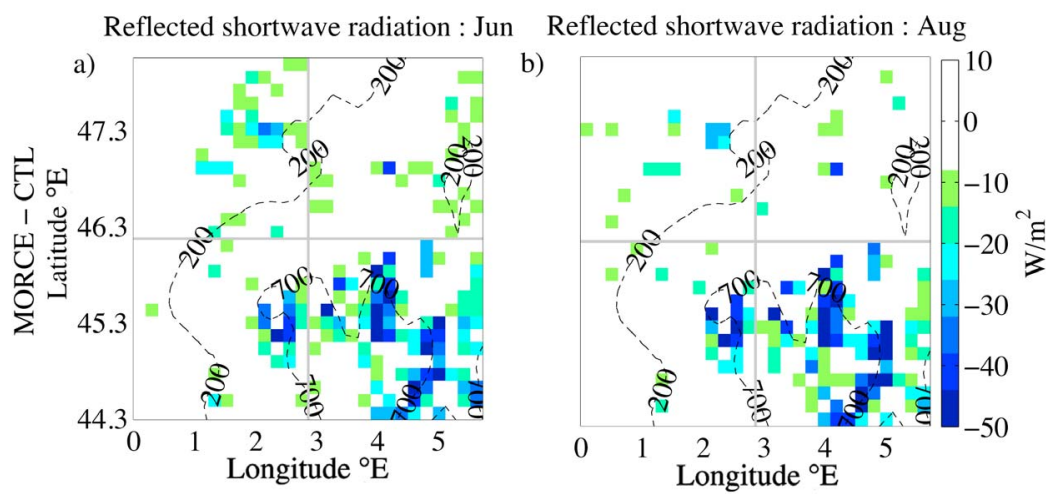

Figure 7. Similar to Figure 5 for the reflected shortwave radiation in (a) June 2003 and (b) August 2003.

the positive difference in LAI is substantially lower there $\left(0.48 \mathrm{~m}^{2} \mathrm{~m}^{-2}\right)$ compared to the Northernmost subdomains $\left(2.05 \mathrm{~m}^{2} \mathrm{~m}^{-2}\right)$. This behavior is not found for the South Eastern sector. In the first half of August, during the heat wave, the South Western subdomain behaves differently from the $\mathrm{NE}$ and NW subdomains since the evapotranspiration deficit in MORCE simulations reaches a peak up to $1.89 \mathrm{~mm} \mathrm{day}^{-1}$. This peak is not observed for the others subdomains. In spite of this important evapotranspiration difference the response in temperature excess $\left(+0.61^{\circ} \mathrm{C}\right)$ is lower than expected, compared to that simulated in the Northern subdomains $\left(+0.37^{\circ} \mathrm{C}\right.$, with $-0.62 \mathrm{~mm}$ day $^{-1}$ for evapotranspiration difference).

\section{Process Analysis}

[30] In order to assess the impact of changing the prescribed vegetation to an interactive one, we give a special attention to the three most likely physical mechanisms. First the soil moisture - precipitation is investigated (section 5.1) in the manner of Beljaars et al. [1996] and Heck et al. [2001]. Then follows a detailed analysis of plant phenology and its link with the hydrological cycle (section 5.2). Last a comparison of vegetation and atmosphere state with an overview of satellite observation is given (section 5.3).

\subsection{The Soil Moisture-Precipitation Feedback}

[31] The main difference of evapotranspiration between the MORCE and CTL runs, for both high and low frequency variability, is driven by the difference of agricultural grass PFT (AC3) transpiration, as suggested by Figure 9. It displays the difference between the MORCE and CTL simulations for the daily average evapotranspiration in the four subdomains and for the various PFTs and bare soil. The residue mainly corresponds to interception loss and other PFT transpiration which are here negligible.
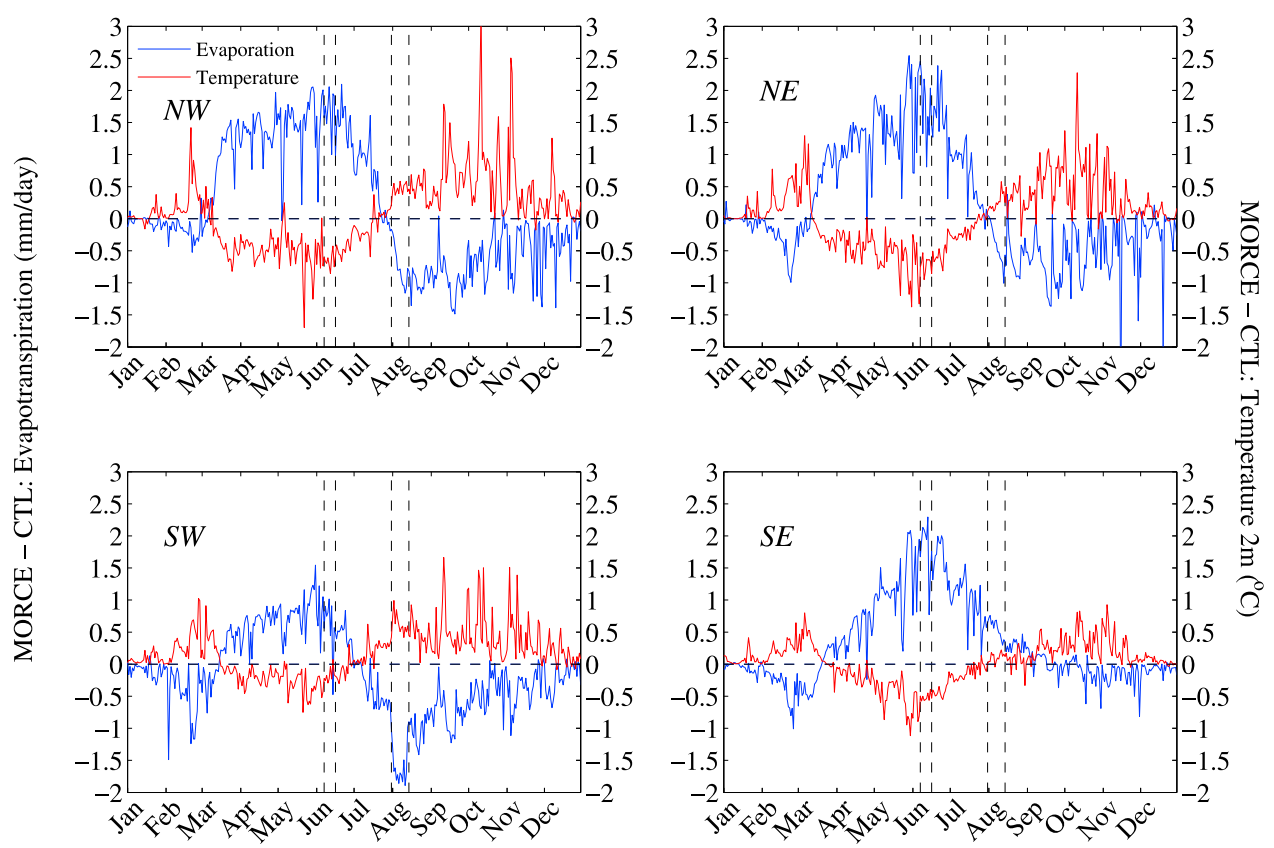

Figure 8. Difference between the MORCE and CTL simulations for the evapotranspiration (blue line) and surface temperature (red line) at 1500 UTC in the North Western subdomain (NW), the North Eastern subdomain (NE), the South Western subdomain (SW) and South Eastern subdomain (SE). Vertical dotted lines delimit the heat waves of June and August. 

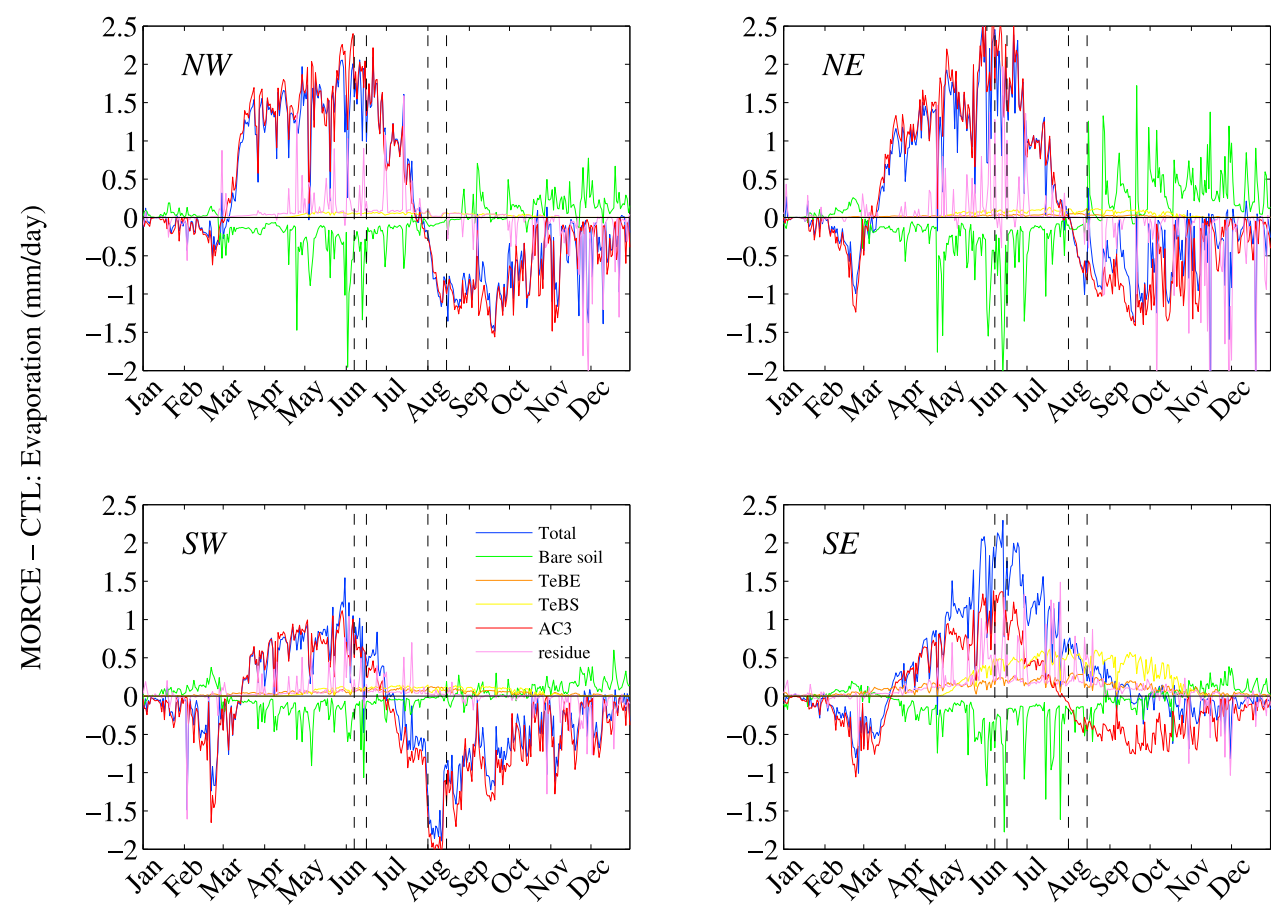

Figure 9. Difference between the MORCE and CTL simulations for the evapotranspiration in the North Western subdomain (NW), the North Eastern subdomain (NE), the South Western subdomain (SW) and South Eastern subdomain (SE) for the different PFTs (temperate broad-leaved evergreen (TBE) in orange, temperate broadleaved summergreen TBS in yellow and agricultural vegetation AC3 in red), bare soil (green), the total (blue) and the residue (purple). Vertical dotted lines delimit the heat waves of June and August.

[32] We find that a subsequent amount of water is evaporated in the MORCE simulation compared to CTL. The additional water may remain in the atmosphere and induces a convective precipitation - soil moisture feedback. Indeed, a water fraction may be immediately recycled through precipitation, change the surface fluxes partition by moisturing the upper soil layers and eventually cool the near-surface atmosphere. In order to investigate a possible soil moistureprecipitation feedback, Figure 10 displays the difference MORCE-CTL of cumulative evapotranspiration (red) and rainfall (blue) in 2003 for the four subdomain. It clearly shows a larger evapotranspiration than precipitation which has dried the soil since March in the MORCE simulation and induced by vegetation green up. Maximum of $P-E T$ occurs during July. This result suggests that this additional water vapor can only be recycled on the domain up to $15.4 \%$ (maximum $P / E T$ ). This is in good agreement with previous results. For instance over the Mediterranean coast, Trenberth [1999] has estimated to $12 \%$ the annual mean recycling, meaning that $12 \%$ of annual precipitation comes from evapotranspiration within the Mediterranean area.

[33] We analyze further rainfall differences during summer (JJA). Convective and large scale rainfall are very similar in MORCE and CTL runs. The departure between cumulated rainfall and rainfall event (rainfall $>0.5 \mathrm{~mm}$ ) during summer is low (close to zero) across the domain. Thus even if there are important differences of surface heat flux, they do not imply the direct onset of few convective rainfall. Although changes in evapotranspiration do not impact strongly local precipitation, it may induce rainfall variations at larger scale outside the domain. In conclusion the evapotranspiration increase causes a slight positive feedback between the vegetation and the rainfall. However, the rainfall enhancement only partially compensates the evapotranspiration increase, and therefore it increases the moisture divergence and the drying.

\subsection{The Role of Phenology Dynamics}

[34] The LAI and the gross primary production (GPP) are diagnostics of the vegetation condition at a given time. The LAI is a partial indicator of the ability of the vegetation to evaporate the water from the root zone soil. GPP is an indicator of the instantaneous activity of the plant, positively correlated with stomata opening and evapotranspiration.

[35] Figure 11 displays similar analysis as Figure 5 but for LAI and GPP. In June, LAI is larger in the MORCE simulation $\left(+1.97 \mathrm{~m}^{2} \mathrm{~m}^{-2}\right.$ on average over the whole domain). In detail, there are large areas of LAI excess in the MORCE simulation compared to the CTL simulation, especially in Northern and South-Eastern France. In these regions, surface temperature is lower in the MORCE simulation which is consistent with a more abundant vegetation and more latent heat flux (Figure 5). Indeed, the correlation between the LAI anomaly pattern and the latent heat flux pattern is very high. As LAI and GPP are partly correlated, Figure $11 \mathrm{~b}$ displays a GPP anomaly pattern similar to the LAI anomaly pattern of Figure $11 \mathrm{a}$, although there are small differences. However, we would expect higher GPP and LAI values, especially in 

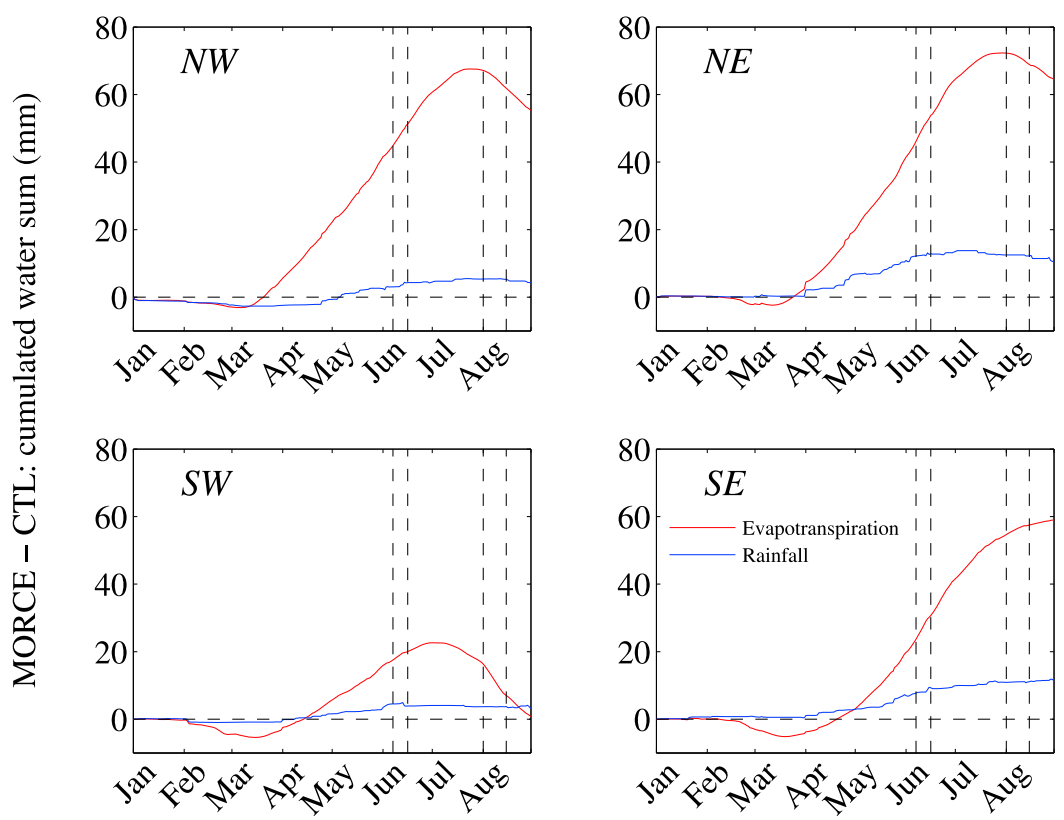

Figure 10. Evolution of the cumulative evapotranspiration (red) and rainfall (blue) in 2003 in the North Western subdomain (NW), the North Eastern subdomain (NE), the South Western subdomain (SW) and South Eastern subdomain (SE). Vertical dotted lines delimit the heat waves of June and August.

the center of the domain which receives more solar radiation in the MORCE simulation during this period (Figure 6b).

[36] In August, GPP is lower in the MORCE simulation by $-1.1 \mathrm{gC} \mathrm{day}^{-1} \mathrm{~m}^{-2}$ with respect to the CTL simulation which corresponds to a decrease of $55 \%$ between June and August. The decrease is almost spatially uniform except in the South-Eastern region on the slopes of the Rhône Valley. A similar pattern is found for LAI, but with more contrast

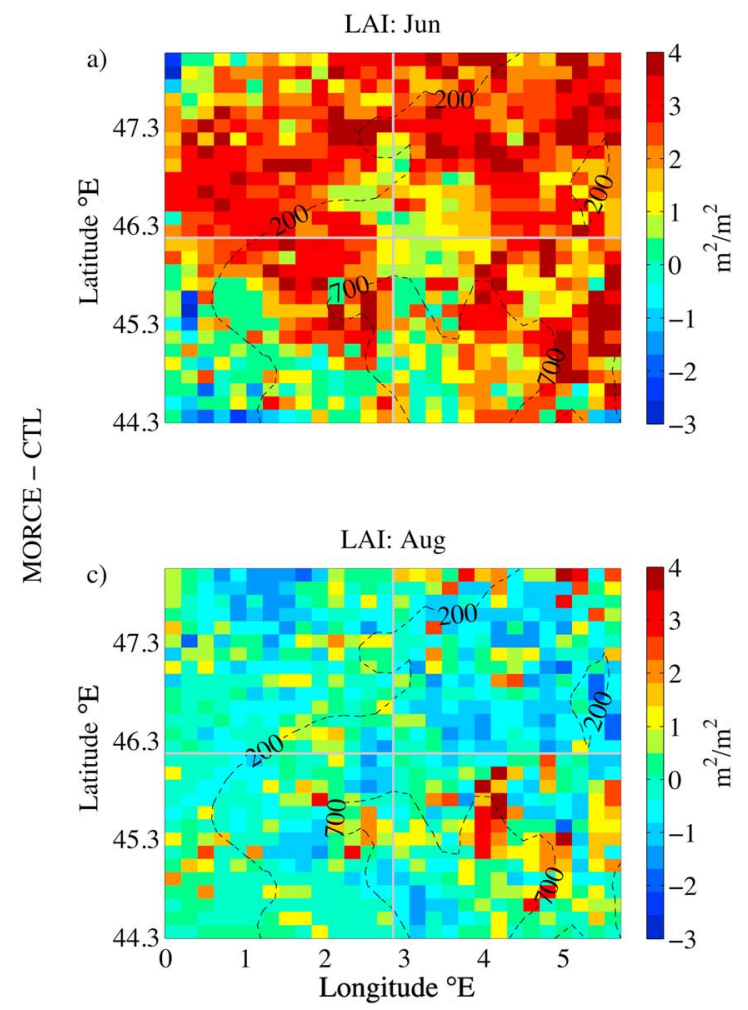

b)

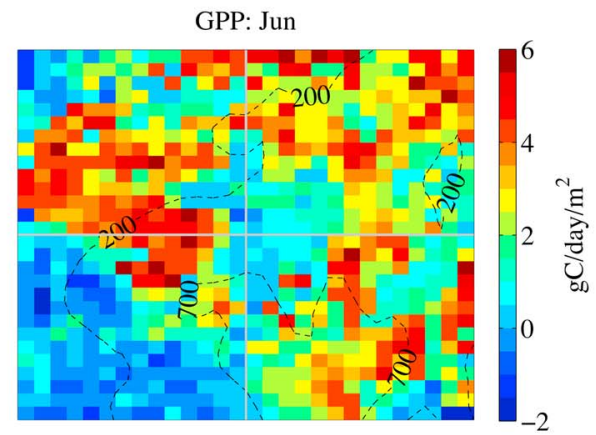

d)

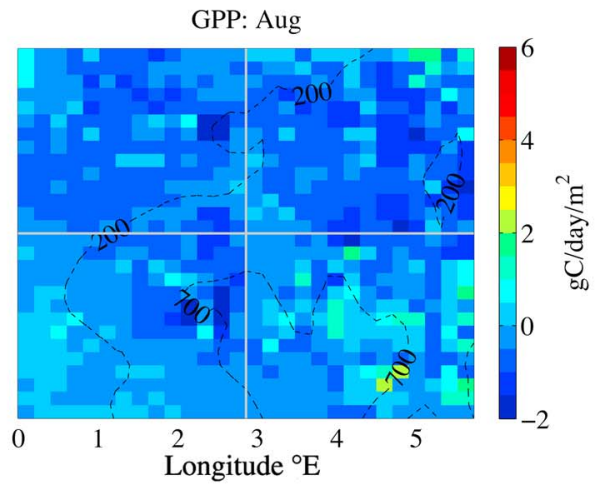

Figure 11. Similar to Figure 5 for (a, c) the leaf area index (LAI) and (b, d) the gross primary production (GPP) in June 2003 (Figures 11a and 11b) and August 2003 (Figures 11c and 11d). 

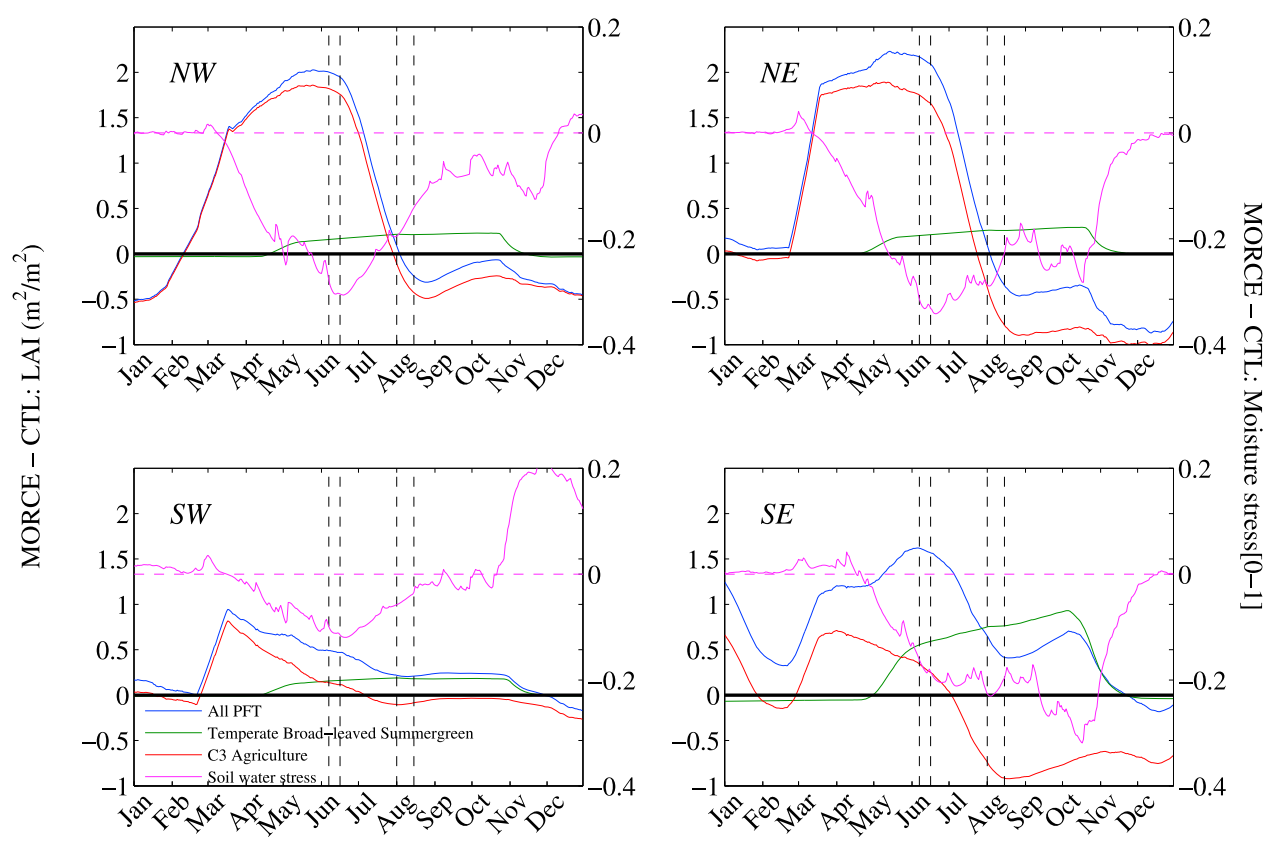

Figure 12. Evolution of the main PFT LAI anomaly (total in blue, TBE and TBS in green and AC3 in red) and water stress index anomaly (purple) in 2003 in the North Western subdomain (NW), the North Eastern subdomain (NE), the South Western subdomain (SW) and South Eastern subdomain (SE). Vertical dotted lines delimit the heat waves of June and August. Left vertical axis is LAI, the right vertical axis uses a different scale for the water stress.

between the regions of higher and lower LAI reduction. Nevertheless the correlation between the LAI anomaly pattern and the latent heat flux pattern is there again high $(0.45)$, but lower than in June (0.55). In contrast the correlation between GPP and latent heat flux is 3 times smaller between June and August. This highlights the link between the vegetation and its foliar surface on the local surface energy budget and the hydrological cycle. In the South Western subdomain, the latent heat flux decreases strongly, while LAI and GPP remain nearly constant. However, in this case, the pattern of temperature anomaly corresponds to the pattern of soil water content anomaly, although the difference between the simulations is low $\left(-3.75 \mathrm{~kg} \mathrm{~m}^{-2}\right)$ compared to the response of others subdomains (not shown). It can not explain differences in latent heat flux up to $100 \mathrm{~W} \mathrm{~m}^{-2}$. One possible explanation is as the soil water content in this subdomain are low $(178 \mathrm{~kg}$ $\mathrm{m}^{-2}$ ), unattainable for the crops, the fall of the latent heat flux is due to a threshold effect of water stress. During August in this subdomain, soil moisture stress for AC3 PFT is critical. It is equal to 0.09 in the MORCE simulation (it is 0.35 in the CTL simulation). Thus only few differences in soil water content leads to large water stress impact for the crops and confirms the presence of a threshold effect.

[37] For a more thorough analysis, we now evaluate the evolution of the LAI anomaly (MORCE-CTL) by PFTs as well as the moisture stress anomaly for the four subdomains (Figure 12). Budburst dates are synchronous in the MORCE and CTL simulations. The seasonal cycle is exacerbated in the MORCE simulation with $40 \%$ additional LAI during the growth phase. This is largely due to the agricultural vegetation (AC3). The temperate broad-leaved summergreen (TBS) LAI has partially offset the early loss of crops in MORCE during the summer to the tune of $+0.3 \mathrm{~m}^{2} \mathrm{~m}^{-2}$. In the southeastern subdomain the crops loss is fully compensated since the TBS LAI is more abundant and the offset is enhanced with almost $+0.8 \mathrm{~m}^{2} \mathrm{~m}^{-2}$ additional LAI. TBS leaf onset and leaf shedding are simultaneous in the two simulations. The exceptional development of TBS in the MORCE simulation (3 times as large as in the CTL simulation) is owing to the sunny conditions and warm weather but also to TBS roots which are 8 times longer than that of AC3 which allow a better withstand to drought. The LAI begins to decline in June in the two simulations. In the MORCE simulation, the LAI declines 15 days earlier than in the CTL simulation. This decline is also much faster in the MORCE simulation. The LAI anomaly changes sign (i.e. the total vegetation becomes less abundant in the MORCE simulation than in the CTL simulation) just before August. Between the date of maximum LAI and 1 September 2003, the LAI drops from 5.4 to $1.5 \mathrm{~m}^{2} \mathrm{~m}^{-2}$ i.e. $-71 \%$ in the MORCE simulation versus $-49 \%$ in the CTL simulation (from 3.45 to $1.75 \mathrm{~m}^{2} \mathrm{~m}^{-2}$ ).

[38] If ORCHIDEE uses 13 PFTs in our simulation domain, more than $95 \%$ of the vegetation is represented by only three PFTs. Here, LAI variations are mainly caused by $\mathrm{C} 3$ crops. From April to June, agricultural C3 grass (AC3) represents $90 \%$ of the foliage surface against $65 \%$ during the heat wave (temperate broad-leaved summergreen and evergreen (TBS and TBE) representing $20 \%$ and $10 \%$, respectively). AC3 PFT evolution strongly depends on moisture availability and temperature. TBS is only function of springtime warmth for onset, computed as an accumulation of non-chilling days. Requirements for senescence are a negative temperature trend and a monthly temperature fall below a given threshold [Krinner et al., 2005]. TBE and evergreen vegetation are not affected by any of these parameters. 

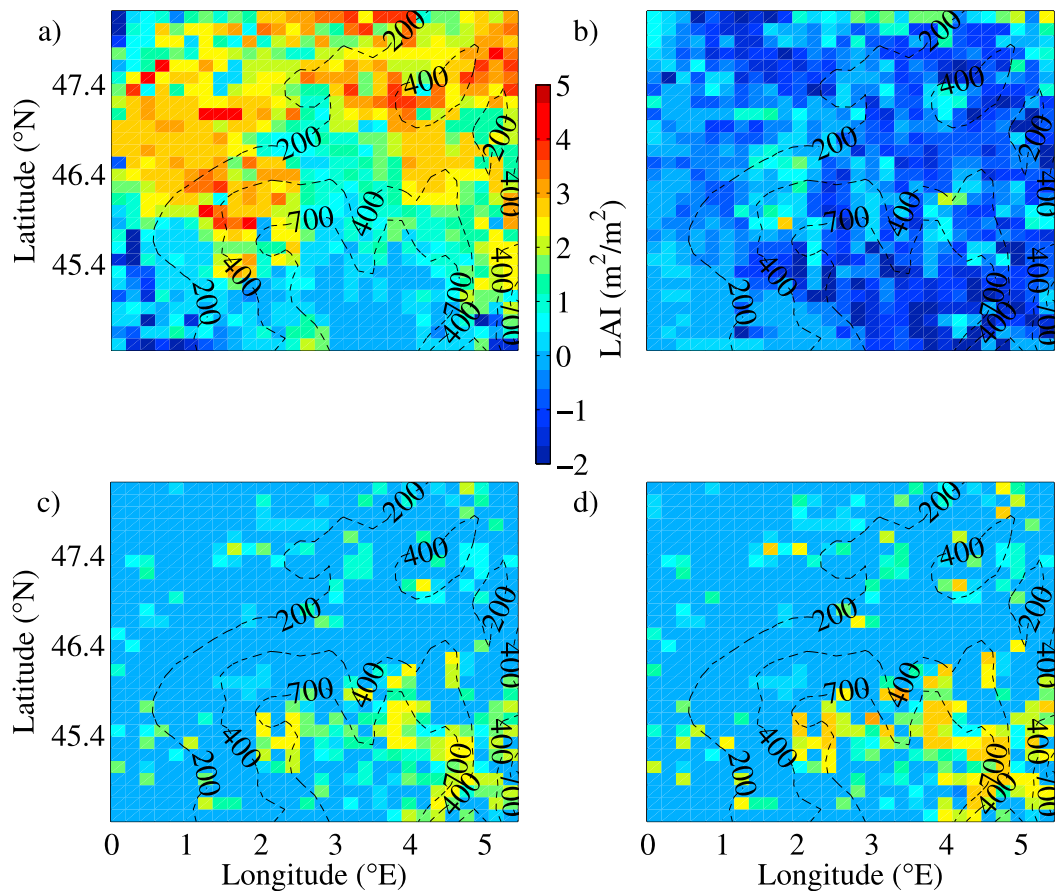

d)

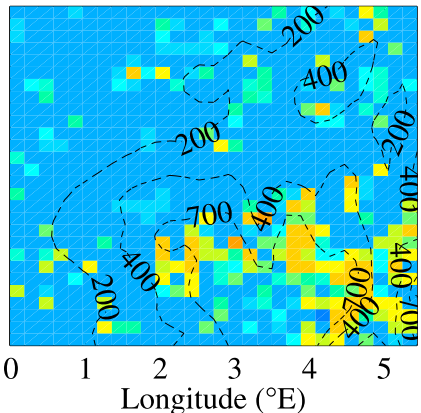

Figure 13. Difference between the MORCE and CTL simulations for (a, b) the agricultural $C_{3}$ grass LAI and (c, d) the forest PFTs LAI for June 2003 (Figures 13a and 13c) and August 2003 (Figures 13b and 13d).

[39] Figures 11 and 13 show evidence that the AC3 is the dominant PFT, accounting for $74 \%$ of total changes in LAI between MORCE and CTL. The others PFTs (Figures 13c and $13 \mathrm{~d}$ ), TBS and TBE forest species are found in large part on the mountain slopes. During August, the LAI anomaly between MORCE and CTL simulation is mostly negative and in large part attributed to AC3 PFT. The positive LAI anomalies associated with forest PFTs (TBS and TBE) persist between June and August heat waves. The positive anomaly even intensifies in the southeastern subdomain. Between June and August, LAI decreases by $-1.83 \mathrm{~m}^{2} \mathrm{~m}^{-2}$ on average, corresponding to $-1.88 \mathrm{~m}^{2} \mathrm{~m}^{-2}$ for AC3 PFT, counterbalanced by $+0.073 \mathrm{~m}^{2} \mathrm{~m}^{-2}$ and $+0.0011 \mathrm{~m}^{2} \mathrm{~m}^{-2}$ for TBS end TBE PFTs, respectively. The AC3 PFT is the main cause of the overall LAI decline during summer.

[40] Since more vegetation requires more soil water, we observe a negative correlation between the water stress and the LAI. Soil moisture stress increases from March to August in the MORCE simulation with respect to the CTL simulation. The level of water stress for AC3 PFT in MORCE becomes very critical in August, almost reaching its maximum value. For the forest PFTs (TBS and TBE), the soil moisture stress is higher in MORCE than CTL but their values remains low compared to agricultural PFT. The difference between the MORCE and CTL simulations increases at the beginning of the growing season, when the MORCE simulation produces leaves massively, and even earlier and more quickly for AC3. After the June heat wave, the vegetation dies in the MORCE simulations. The difference of soil moisture stress decreases. It indicates that the vegetation does not pump water anymore whereas in the CTL simulation, this process is not interrupted. Senescence in the CTL simulation is thus most likely caused by leaf age whereas in the MORCE simulation, senescence occurs earlier by about two weeks and is induced by water stress which reaches a critical threshold.

[41] The moisture supply from the soil to the atmosphere thus decreases during summer, and drought effect is enhanced especially for $\mathrm{C} 3$ crops, due to a root profile less deep than others PFT as broad leaved-trees. Figure 14 shows that trees, in both MORCE and CTL, have an evapotranspiration around $5.8 \mathrm{~mm}$ day $^{-1}$, whatever the soil moisture is between $180 \mathrm{~mm}$ and $300 \mathrm{~mm}$ (which is more than $50 \%$ of the maximum water available for plants in our model). Crops on the other had have similar evapotranspiration rates (slightly lower) when soil moisture exceeds $220 \mathrm{~mm}$ but the rates start to decrease with soil moisture below this "critical" value. In 2002 the domain remain permanently in an energy limited evapotranspiration regime, while in 2003 cropland areas switch to soil moisture limited after the heat wave. This change is not observed for forested ecosystem, because water stress is not important enough, as suggested by the high transpiration rate. The difference of response over cropland and forested areas can explain that evapotranspiration is higher in South Eastern subdomain for the MORCE simulation during August. As already stated by Teuling et al. [2010], grasses (with a similar behavior than crops) can evaporate more than trees during heat waves as long as moisture is not limited. On long term the conservative water use of trees mitigates drought effect whereas the crops collapse.

[42] Evapotranspiration evolution through summer is consistent with expectation, as the shallow-rooted vegetation typical agricultural land does not have access to deeper reservoirs of water. It dries more quickly than deeper-rooted forest vegetation during a drought, leading to a rapid increase in sensible heat flux and temperature [Shukla et al., 1990]. The repartition between cropland and forested area leads to 

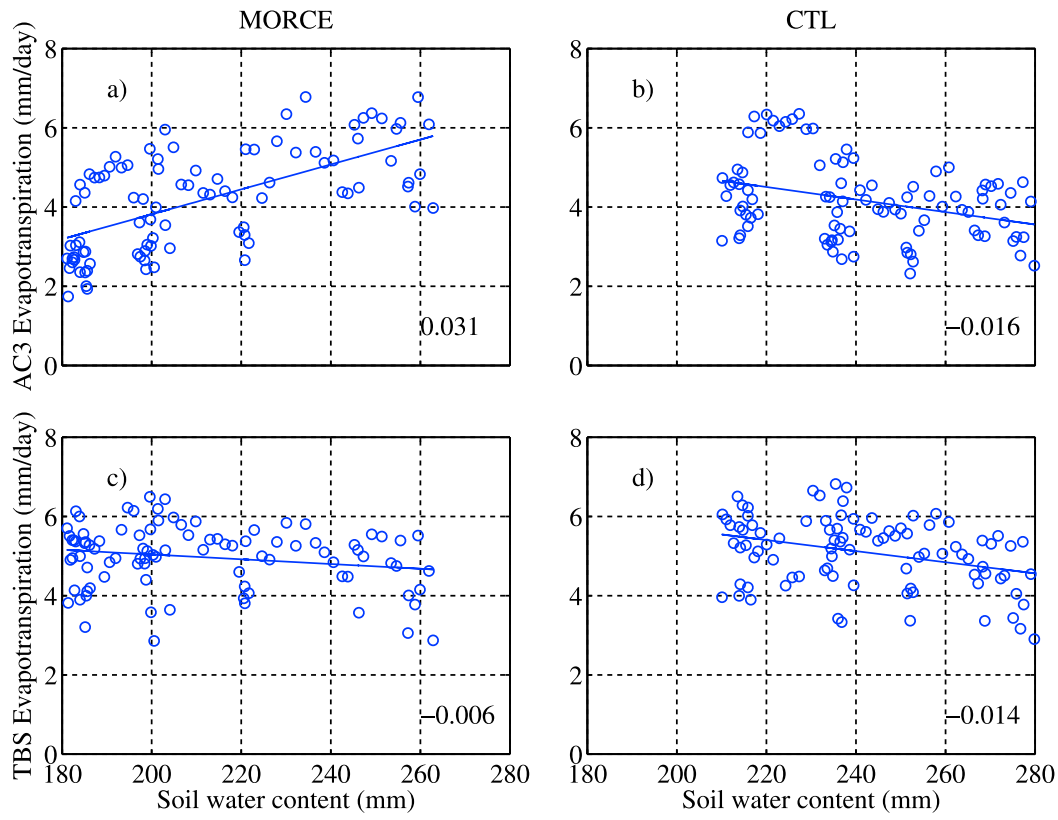

Figure 14. Soil water content and evapotranspiration daily values at 1500 UTC averaged over domain for MORCE and CTL runs during summer $(\mathrm{JJA})(\mathrm{a}, \mathrm{b})$ for the agricultural $C_{3}$ grass and $(\mathrm{c}, \mathrm{d})$ for the forest PFTs. Linear regressions are added in respective colors, and the slope values are indicated in the bottom right corner.

the temperature anomaly pattern between the MORCE and CTL simulations during the heat waves (Figure 5).

[43] As a summary, Figure 15 displays a comparison of Bowen ratio, Net Primary Production (NPP) and LAI times series between the MORCE and CTL simulations. For legibility, the curves are smoothed with a 21-day running mean. LAI and NPP indicate a doubling of the vegetation in the MORCE simulation, with LAI peak occurring two weeks earlier. This vegetation surplus induces a higher latent flux and therefore a lower Bowen ratio, until the crops collapse due to the drought. Afterward the loss of agricultural vegetation and the moisture depletion enhances the Bowen ratio in MORCE with higher temperature during the August heatwave. Consequently the dominance change of the Bowen ratio is related to phenology and soil moisture.

\subsection{Comparison With Previous Studies}

[44] Several studies with satellite imagery have been performed to check the state of the vegetation during 2003. Their conclusions are consistent with the results of this paper. The shortening of the growing season in the MORCE simulation and the difference between crop and forested area (section 5.2) are in good agreement with [Zaitchik et al., 2006]. An analysis of NDVI time series points out two distinct temporal trends to the vegetative cycle. The springtime warmth led to an early green up represented by positive values of NDVI anomaly whereas in June, the fall of leaves begins, and will become more severe later in summer (negative values of NDVI anomaly). This is particularly true for areas classified as pastures or active crops. Similarly Teuling et al. [2010] showed that the heat waves response was ecosystem specific and the most significant for croplands. Moreover the analysis of the photosynthetic activity of the Swiss Alps forest during 2003 summer heat wave have suggested an enhancement of vegetation growth in altitude (higher than $1400 \mathrm{~m}$ ) and an opposite trend at lower altitude [Jolly et al., 2005] which qualitatively validates our sensitivity study (Figure 11). An explanation is the lengthening of the free-snow season at high elevation and an increase of the evaporative demand at lower elevation. In our study, if we reach the same conclusions we assert that the kind of ecosystem is also a main factor for this elevation effect. However, if cold weather, chilling days and snow cover influence LAI evolution in our LSM, as it was pointed out earlier, the beginning of the growing season is identical between the MORCE and CTL simulations. LAI is only enhanced by solar radiation and higher temperature more appropriate and closer to the optimum photosynthetic. Otherwise senescence occurs earlier in MORCE for agricultural grass, due to the water stress.

\section{Conclusion}

[45] This article highlights the effect of dynamical vegetation on the two heat waves that hit Europe during summer 2003. The first heat wave occurred in the second week of June whereas the better known event which had dramatic consequences occurred during the first 15 days of August.

[46] By conducting two high resolution simulations over France, one with prescribed vegetation phenology set to the 2002 behavior and one letting the phenology respond to climate extremes, we found that the vegetation contributes to damp the temperature anomaly in June 2003, while it amplifies the temperature anomaly in August 2003. The two summer 2003 heat waves were preceded by several months of cloudiness and precipitation deficit. Solar radiation was unusually high which was beneficial for vegetation growth. The evolution of the leaf-area index in the two simulations 

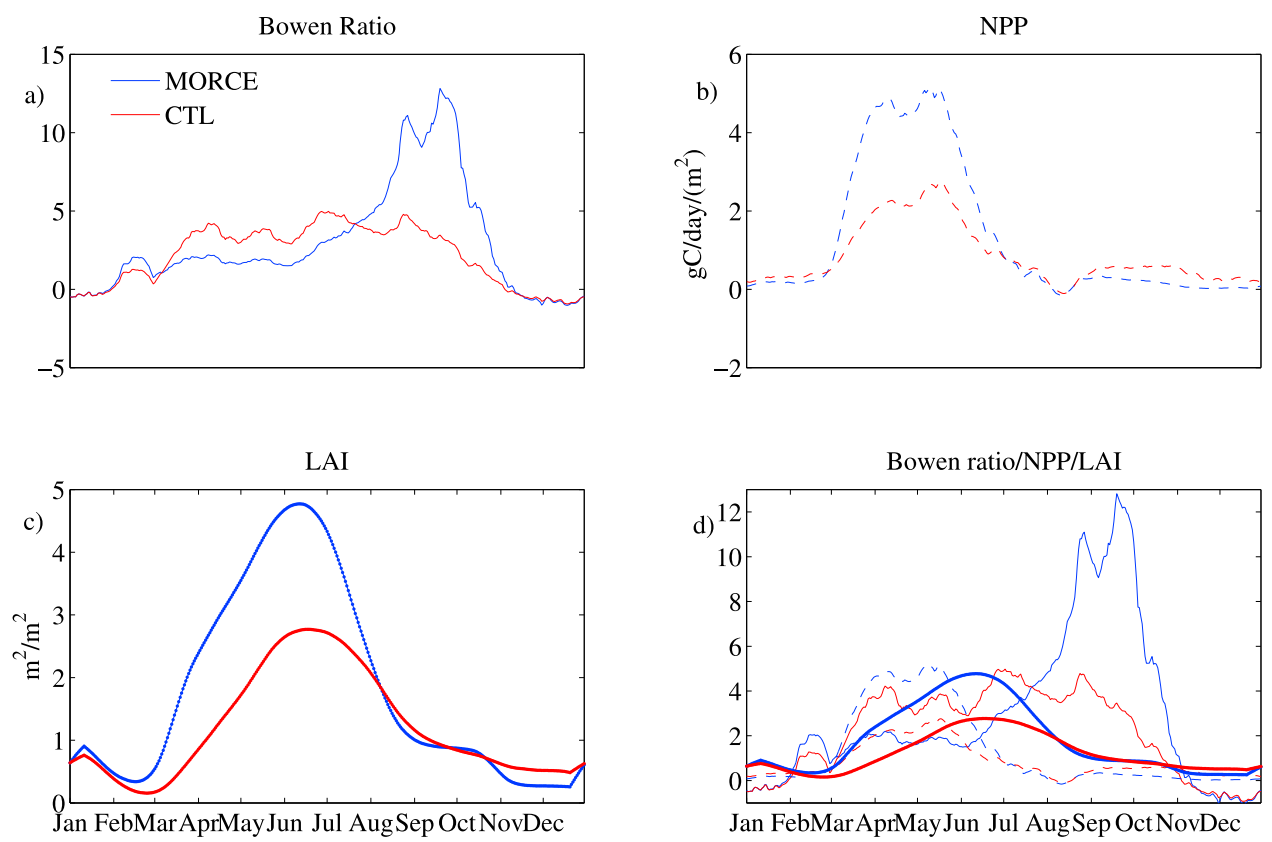

Figure 15. Bowen ratio (thin line), Net Primary Production (NPP) (dashed line) and LAI (thick line) times series from January to December 2003, for MORCE (blue) and CTL (red) simulations. The curves have been smoothed using a 21-day running mean.

reveals an early development of agricultural vegetation in the simulation with freely evolving vegetation. This unusual excess of vegetation lasts until end of July when the vegetation start dying. This behavior has two consequences:

[47] 1. In June, the excess of agricultural vegetation, caused by high springtime insolation, contributes to increase evapotranspiration and thus more surface cooling, and damping of the temperature anomaly during the heat wave. This effect is not as visible in mountainous regions where the presence of forest and the absence of agriculture do not lead to a modulation of the local water cycle.

[48] 2. In August, the critical soil moisture stress contribute to suppress any evapotranspiration and to enhance sensible heat flux thus amplifying the temperature anomaly during the heat wave. In the northern part of the domain, the death of agricultural vegetation contributes also to reduce the evapotranspiration.

[49] As also shown in previous studies, water recycling contributes at most to 10 to $20 \%$, thus proving the significant contribution of the effect of the vegetation dynamics on the local to regional water cycle. For the two heat waves, the temperature anomaly that can be attributed to the effect of dynamical vegetation can reach $\pm 1.5^{\circ} \mathrm{C}$ for an average total anomaly of about $8^{\circ} \mathrm{C}$ [Feudale and Shukla, 2010], which represents a $20 \%$ contribution. This is not negligible and is half of the contribution of soil water deficit during the August heat wave which is often seen as a key driving process for heat wave occurrence [Fischer et al., 2007]. We are also aware that agricultural PFT, the main ecosystem in our study, is one of the most difficult vegetation type to model. Although this PFT parameterization requires improvement to get a more realistic simulation [Smith et al., 2010], this coupling already emphasizes that vegetation atmosphere interactions are a major component of the spatial pattern of an extreme event.
[50] One aspect that has not been addressed is the role of the atmospheric chemistry (e.g. ozone) which also has a direct effect on plant stomatal structure [Anav et al., 2011]. Indeed, summer heat waves are associated with high insolation and low cloudiness. In nearby urban areas, these conditions are also favorable to strong pollution levels, with especially high ozone concentration. Future work will investigate the additional effect of the severe pollution episode of August 2003 on the temperature anomaly during the summer heat wave.

[51] Acknowledgments. This work has been supported by the MORCE-MED and Humboldt projects funded by the GIS (Groupement d'Intérêt Scientifique) Climat, Environnement et Société. This work also contributes to the HyMeX program (HYdrological cycle in the Mediterranean EXperiment [Drobinski et al., 2009, 2010]) through INSU-MISTRALS support and the GEWEX program of WCRP. The authors are thankful to J. Polcher for fruitful discussions and to A. Anav, M. Mancip and N. Viovy for technical support.

\section{References}

Anav, A., F. D'Andrea, N. Viovy, and N. Vuichard (2010), A validation of heat and carbon fluxes from high-resolution land surface and regional models, J. Geophys. Res., 115, G04016, doi:10.1029/2009JG001178.

Anav, A., L. Menut, D. Khvorostyanov, and N. Viovy (2011), Impact of tropospheric ozone on the Euro-Mediterranean vegetation, Global Change Biol., 17, 2342-2359.

Ball, J. T. (1987), A model predicting stomatal conductance and its contribution to the control of photosynthesis under different environmental conditions, in Progress in Photosynthesis Research: Proceedings of the VIIth International Congress on Photosynthesis, Providence, Rhode Island, USA, August 10-15, 1986, vol. 4, edited by J. Biggins, pp. 221-224, M. Nijhoff, Dordrecht, Netherlands.

Ballester, J., F. Giorgi, and X. Rodó (2010), Changes in European temperature extremes can be predicted from changes in pdf central statistics, Clim. Change, 98, 277-284.

Baret, F., H. Makhmara, R. Lacaze, and B. Smets (2012), Biopar product user manual LAI, FAPAR, FCover, NDVI version 1 from SPOT/VEGETATION data, EC Proposal FP-7-218795, Geoland2, Immenstaad, Germany.

Barriopedro, D., E. M. Fischer, J. Luterbacher, R. M. Trigo, and R. GarciaHerrera (2011), The hot summer of 2010: Redrawing the temperature record map of Europe, Science, 332, 220-224. 
Beljaars, A., P. Viterbo, M. Miller, and A. Betts (1996), The anomalous rainfall over the United States during July 1993: Sensitivity to land surface parameterization and soil moisture anomalies, Mon. Weather Rev., $124,362-383$.

Beniston, M. (2004), The 2003 heat wave in Europe: A shape of things to come? An analysis based on Swiss climatological data and model simulations, Geophys. Res. Lett., 31, L02202, doi:10.1029/2003GL018857.

Bonan, G. B., S. Levis, S. Sitch, M. Vertenstein, and K. W. Oleson (2003), A dynamic global vegetation model for use with climate models: Concept and description of simulated vegetation dynamics, Global Change Biol. 9, 1543-1566.

Bounoua, L., S. O. Collatz, G. Jand Los, P. J. Sellers, D. A. Dazlich, C. J. Tucher, and D. A. Randall (2000), Sensitivity of climate to changes in NDVI, J. Clim., 13, 2277-2292.

Choisnel, E., S. V. Jourdain, and C. J. Jacquart (1995), Climatological evaluation of some fluxes of the surface energy and soil water balances over france, Ann. Geophys., 13, 666-674.

Christensen, J. H., and O. B. Christensen (2003), Severe summertime flooding in Europe, Nature, 421, 805-806.

Ciais, P., et al. (2005), Europe-wide reduction in the primary productivity caused by the heat and drought in 2003, Nature, 437, 529-533.

Collatz, G. J., J. T. Ball, C. Grivet, and J. A. Berry (1991), Physiological and environmental regulation of stomatal conductance, photosynthesis and transpiration: a model that includes a laminar boundary layer, Agric. For. Meteorol., 54, 107-136.

COPA-COGECA (2003), Assessment of the impact of the heat wave and drought of the summer 2003 on agriculture and forestry, technical report, Brussels.

Dee, D. P., et al. (2011), The ERA-Interim reanalysis: Configuration and performance of the data assimilation system, Q. J. R. Meteorol. Soc., 137, 553-597.

Della-Marta, P. M., M. R. Haylock, J. Luterbacher, and H. Wanner (2007), Doubled length of western European summer heat waves since 1880 , J. Geophys. Res., 112, D15103, doi:10.1029/2007JD008510.

De Rosnay, P., and J. Polcher (1998), Modeling root water uptake in a complex land surface scheme coupled to a GCM, Hydrol. Earth Syst. Sci., 2, 239-256.

Drobinski, P., V. Ducrocq, P. Lionello, and HyMeX ISSC (2009), Hymex, a potential new CEOP RHP in the Mediterranean basin, GEWEX Newsl., 19, 5-6.

Drobinski, P., V. Ducrocq, and P. Lionello (2010), Studying the hydrological cycle in the Mediterranean, Eos Trans. AGU, 91, 373.

Drobinski, P., et al. (2012), Model of the regional coupled Earth system (MORCE): Application to process and climate studies in vulnerable regions, Environ. Modell. Software, 35, 1-18.

Ducoudré, N., K. Laval, and A. Perrier (1993), SECHIBA, a new set of parametrizations of the hydrologic exchanges at the land/atmosphere interface within the lmd atmospheric general circulation model, J. Clim., $6,248-273$

Dudhia, J. (1989), Numerical study of convection observed during the winter monsoon experiment using a mesoscale two-dimensional model, J. Atmos. Sci., 46, 3077-3107.

Easterling, D. R., G. A. Meehl, C. Parmesan, S. A. Changnon, T. R. Karl, and L. O. Mearns (2000), Climate extremes: Observations, modeling, and impacts, Science, 289, 2068-2074.

Eckel, T. (2002), Perturbing MM5 moisture availability for ensemble forecasting, technical report, Univ. of Washington, Seattle.

Ellis, F. H., H. Prince, G. Lovatt, and R. Whittington (1980), Mortality and morbidity in Birmingham during the 1976 heat wave, Q. J. Med., 49, 1-8.

Farquhar, G. D., S. Caemmerer, and J. A. Berry (1980), A biochemical model of photosynthetic $\mathrm{CO}_{2}$ assimilation in leaves of $\mathrm{C}_{3}$ species, Planta, 149, 78-90.

Ferranti, L., and P. Viterbo (2006), The European summer of 2003: Sensitivity to soil water initial conditions, J. Clim., 19, 3659-3680.

Feudale, L., and J. Shukla (2010), Influence of sea surface temperature on the European heat wave of 2003 summer. Part I: An observational study, Clim. Dyn., 36, 1691-1703.

Fink, A. H., T. Bruecher, G. C. Leckebusch, A. Krueger, J. G. Pinto, and U. Ulbrich (2004), The 2003 European summer heatwaves and drought - Synopstic diagnosis and impacts, Weather, 59, 209-216.

Fischer, E. M., and C. Schär (2010), Consistent geographical patterns of changes in high-impact European heatwaves, Nat. Geosci., 3, 398-403.

Fischer, E. M., S. I. Seneviratne, P. L. Vidale, D. Lüthi, and C. Schär (2007), Soil moisture-atmosphere interactions during the 2003 European summer heat wave, J. Clim., 20, 5081-5099.

Flaounas, E., P. Drobinski, M. Vrac, S. Bastin, C. Lebeaupin-Brossier, M. Stéfanon, M. Borga, and J.-C. Calvet (2012), Precipitation and temperature space-time variability and extremes in the Mediterranean region:
Evaluation of dynamical and statistical downscaling methods, Clim. Dyn., in press.

Foley, J., S. Levis, I. C. Prentice, D. Pollard, and S. Thompson (1998), Coupling dynamic models of climate and vegetation, Global Change Biol., 4, $561-579$.

Garcia-Herrera, R., J. Diaz, R. M. Trigo, J. Luterbacher, and E. Fischer (2010), A review of the European summer heat wave of 2003, Crit. Rev. Environ. Sci. Technol., 40, 267-306.

Giorgi, F., C. Jones, and G. R. Asrar (2009), Addressing climate information needs at the regional level: The CORDEX framework, WMO Bull., $58,175-183$.

Haylock, M. R., N. Hofstra, A. M. G. Klein Tank, E. J. Klok, P. D. Jones, and M. New (2008), A European daily high-resolution gridded data set of surface temperature and precipitation for 1950-2006, J. Geophys. Res., 113, D20119, doi:10.1029/2008JD010201.

Heck, P., D. Lüthi, H. Wernli, and C. Schär (2001), Climate impacts of European-scale anthropogenic vegetation changes: A sensitivity study using a regional climate model, J. Geophys. Res., 106, 7817-7835.

Hémon, D., and E. Jougla (2003), Surmortalité liée à la canicule d'Août 2003, technical report, Inst. Natl. de la Santé et de la Rech. Méd., Paris.

Hong, S. Y., J. Dudhia, and S.-H. Chen (2004), A revised approach to ice microphysical processes for the bulk parameterization of clouds and precipitation, Mon. Weather Rev., 132, 103-120.

Jolly, W. M., M. Dobbertin, N. E. Zimmermann, and M. Reichstein (2005), Divergent vegetation growth responses to the 2003 heat wave in the Swiss Alps, Geophys. Res. Lett., 32, L18409, doi:10.1029/2005GL023252.

Jung, M., et al. (2007), Uncertainties of modeling gross primary productivity over Europe: A systematic study on the effects of using different drivers and terrestrial biosphere models, Global Biogeochem. Cycles, 21, GB4021, doi:10.1029/2006GB002915.

Kain, J. S. (2004), The Kain-Fritsch convective parameterization: An update, J. Appl. Meteorol., 43, 170-181.

Keenan, T., R. García, A. D. Friend, S. Zaehle, C. Gracia, and S. Sabate (2009), Improved understanding of drought controls on seasonal variation in mediterranean forest canopy $\mathrm{CO}_{2}$ and water fluxes through combined in situ measurements and ecosystem modelling, Biogeosciences, 6, 1423-1444.

Klein Tank, A. M. G., and G. P. Konnen (2003), Trends in indices if daily temperature and precipitation extremes in Europe, J. Clim., 16, 3665-3680.

Klein Tank, A. M. G., G. P. Konnen, and F. M. Selten (2005), Signals of anthropogenic influence on European warming as seen in the trend patterns of daily temperature variance, Int. J. Climatol., 25, 1-16.

Köppen, W. (1936), Das geographisca system der klimate, Handb. Klimatol., $25,1-44$.

Krinner, G., N. Viovy, N. de Noblet-Ducoudré, J. Ogeé, J. Polcher, P. Friedlingstein, P. Ciais, S. Sitch, and I. Colin Prentice (2005), A dynamic global vegetation model for studies of the coupled atmosphere-biosphere system, Global Biogeochem. Cycles, 19, GB1015, doi:10.1029/ 2003 GB002199.

Levinson, D. H., and A. M. Waple (2004), State of the climate in 2003, Bull. Am. Meteorol. Soc., 85, S1-S72.

Loew, A., T. Holmes, and R. de Jeu (2009), The European heat wave 2003: Early indicators from multisensoral microwave remote sensing?, J. Geophys. Res., 114, D05103, doi:10.1029/2008JD010533.

Loveland, T. R., B. C. Reed, J. F. Brown, D. O. Ohlen, Z. Zhu, L. Yang, and J. W. Merchant (2000), Development of a global land cover characteristics database and IGBP DISCover from $1 \mathrm{~km}$ AVHRR data, Int. J. Remote Sens., 21, 1303-1330.

Lu, L., and W. J. Shuttleworth (2002), Incorporating NDVI-derived LAI into the climate version of RAMSs and its impact on regional climate, J. Hydrometeorol., 3, 347-362.

Luterbacher, J., D. Dietrich, E. Xoplaki, M. Grosjean, and H. Wanner (2004), European seasonal and annual temperature variability, trends, and extremes since 1500, Science, 303, 1499-1503.

Mahecha, M. D., et al. (2010), Comparing observations and process-based simulations of biosphere-atmosphere exchanges on multiple timescales, J. Geophys. Res., 115, G02003, doi:10.1029/2009JG001016.

Mlawer, E. J., S. J. Taubnam, P. D. Brown, M. J. Iacono, and S. A. Clough (1997), A validated correlated k-model for the longwave, J. Geophys. Res., 102, 1663-1682.

Monin, A. S., and A. M. Obukhov (1954), Basic laws of turbulent mixing in the surface layer of the atmosphere, Contrib. Geophys. Inst. Acad. Sci., $151,163-187$.

Morales, P., et al. (2005), Comparing and evaluating process-based ecosystem model predictions of carbon and water fluxes in major European forest biomes, Global Change Biol., 11, 2211-2233. 
Noh, Y., W. G. Cheon, S.-Y. Hong, and S. Raasch (2003), Improvement of the k-profile model for the planetary boundary layer based on large eddy simulation data, Boundary Layer Meteorol., 107, 401-427.

Omrani, H., P. Drobinski, and T. Dubos (2012), Spectral nudging in regional climate modelling: How strongly should we nudge?, $Q$. $J . R$. Meteorol. Soc., 138, 1808-1813, doi:10.1002/qj.1894.

Peel, M. C., B. L. Finlayson, and T. A. McMahon (2007), Updated world map of the Köppen-geiger climate classification, Hydrol. Earth Syst. Sci. Discuss., 4, 439-473.

Räisänen, J. (2002), $\mathrm{CO}_{2}$-induced changes in interannual temperature and precipitation variability in 19 CMIP2 experiments, J. Clim., 15, 2395-2411.

Reichstein, M., et al. (2007), Reduction of ecosystem productivity and respiration during the European summer 2003 climate anomaly: A joint flux tower, remote sensing and modelling analysis, Global Change Biol., 13, 634-651.

Robine, J.-M., S. L. K. Cheung, S. Le Roy, H. Van Oyen, C. Griffiths, J.-P. Michel, and F. R. Herrmann (2008), Death toll exceeded 70,000 in Europe during the summer of 2003, C. R. Biol., 331(2), 171-178.

Santaren, D., P. Peylin, N. Viovy, and P. Ciais (2007), Optimizing a process-based ecosystem model with eddy-covariance flux measurements A pine forest in southern France, Global Biogeochem. Cycles, 21, GB2013, doi:10.1029/2006GB002834.

Schär, C., P. L. Vidale, D. Lüthi, C. Frei, C. Haberli, M. A. Liniger, and C. Appenzeller (2004), The role of increasing temperature variability in European summer heatwaves, Nature, 427, 332-336.

Semenza, J. C., C. H. Rubin, K. H. Falter, J. D. Selanikio, W. D. Flanders, H. L. Howe, and J. L. Wilhelm (1996), Heat-related deaths during the July 1995 heat wave in Chicago, N. Engl. J. Med., 335, 84-90.

Shukla, J., C. Nobre, and P. J. Sellers (1990), Amazon deforestation and climate change, Science, 247, 1322-1325.

Simons, A., S. Uppala, D. Dee, and S. Kobayashi (2007), ERA-Interim: New ECMWF reanalysis products from 1989 onwards, ECMWF Newsl., $110,25-35$

Skamarock, W. C., J. B. Klemp, J. Dudhia, D. O. Gill, D. M. Barker, M. G. Duda, X.-Y. Huang, W. Wang, and J. G. Powers (2008), A description of the advanced research WRF version 3, Tech. Note NCAR/TN-475+STR, Natl. Cent. for Atmos. Res., Boulder, Colo.

Smirnova, T. G., J. M. Brown, and S. G. Benjamin (1997), Performance of different soil model configurations in simulating ground surface temperature and surface fluxes, Mon. Weather Rev., 125, 1870-1884.

Smirnova, T. G., J. M. Brown, S. G. Benjamin, and D. Kim (2000), Parameterization of cold season processes in the maps land-surface scheme, J. Geophys. Res., 105, 4077-4086.

Smith, P. C., N. De Noblet-Ducoudré, P. Ciais, P. Peylin, N. Viovy, Y. Meurdesoif, and A. Bondeau (2010), European-wide simulations of croplands using an improved terrestrial biosphere model: Phenology and productivity, J. Geophys. Res., 115, G01014, doi:10.1029/ 2008JG000800
Stéfanon, M., F. D’Andrea, and P. Drobinski (2012), Heatwave classification over Europe and the Mediterranean region, Environ. Res. Lett., 7(1), 014023, doi:10.1088/1748-9326/7/1/014023.

Szczypta, C. (2012), Space hydrology for the monitoring of mediterranean droughts, PhD thesis, Inst. Natl. Polytech. de Toulouse, Toulouse, France.

Tank, A. M. G. K., et al. (2002), Daily dataset of 20th-century surface air temperature and precipitation series for the European climate assessment, Int. J. Climatol., 22, 1441-1453.

Teuling, A. J., et al. (2010), Contrasting response of European forest and grassland energy exchange to heatwaves, Nat. Geosci., 3, 722-727.

Trenberth, K. E. (1999), Atmospheric moisture recycling: Role of advection and local evaporation, J. Clim., 12, 1368-1381.

van der Velde, M., F. Tubiello, A. Vrieling, F. Bouraoui, M. Velde, F. N. Tubiello, A. Vrieling, and F. Bouraoui (2011), Impacts of extreme weather on wheat and maize in France: Evaluating regional crop simulations against observed data, Clim. Change, 113, 751-765, doi:10.1007/ s10584-011-0368-2

Vautard, R., C. Honoré, M. Beekman, and L. Rouil (2005), Simulation of ozone during heat wave and emission control scenarios, Atmos. Environ., 39, 2957-2967.

Vautard, R., P. Yiou, F. D'Andrea, N. de Noblet, N. Viovy, C. Cassou, J. Polcher, P. Ciais, M. Kageyama, and Y. Fan (2007), Summertime European heat and drought waves induced by wintertime mediterranean rainfall deficit, Geophys. Res. Lett., 34, L07711, doi:10.1029/2006GL028001.

Vetter, M., et al. (2008), Analyzing the causes and spatial pattern of the European 2003 carbon flux anomaly using seven models, Biogeosciences, $5,561-583$.

Viovy, N., and N. de Noblet-Ducoudré (1997), Coupling water and carbon cycle in the biosphere, Sci. Geol. Bull., 50, 109-121.

Wilson, M., and A. Henderson-Sellers (1985), A global archive of land cover and soils data for use in general circulation models, J. Climatol., $5,119-143$.

Xoplaki, E., et al. (2012), Large-Scale Atmospheric Circulation Driving Extreme Climate Events in the Mediterranean and Its Related Impacts, chap. 6, pp. 347-365, Elsevier, New York.

Zaitchik, B. F., A. K. Macalady, L. R. Bonneau, and R. B. Smith (2006), Europe's 2003 heat wave: A satellite view of impacts and land-atmosphere feedbacks, Int. J. Climatol., 26, 743-769.

Zampieri, M., F. D’Andrea, R. Vautard, P. Ciais, N. de Noblet-Ducoudré, and P. Yiou (2009), Hot European summers and the role of soil moisture in the propagation of Mediterranean drought, J. Clim., 22, 4747-4758. 